\title{
Near-surface snow particle dynamics from particle tracking velocimetry and turbulence measurements during alpine blowing snow storms
}

\author{
Nikolas O. Aksamit and John W. Pomeroy \\ Centre for Hydrology, University of Saskatchewan, Saskatoon, S7N 5C8, Canada \\ Correspondence to: Nikolas O. Aksamit (n.aksamit@usask.ca) \\ Received: 20 April 2016 - Published in The Cryosphere Discuss.: 3 May 2016 \\ Revised: 15 November 2016 - Accepted: 15 November 2016 - Published: 16 December 2016
}

\begin{abstract}
Many blowing snow conceptual and predictive models have been based on simplified two-phase flow dynamics derived from time-averaged observations of bulk flow conditions in blowing snow storms. Measurements from the first outdoor application of particle tracking velocimetry (PTV) of near-surface blowing snow yield new information on mechanisms for blowing snow initiation, entrainment, and rebound, whilst also confirming some findings from wind tunnel observations. Blowing snow particle movement is influenced by complex surface flow dynamics, including saltation development from creep that has not previously been measured for snow. Comparisons with 3-D atmospheric turbulence measurements show that blowing snow particle motion immediately above the snow surface responds strongly to high-frequency turbulent motions. Momentum exchange from wind to the dense near-surface particle-laden flow appears significant and makes an important contribution to blowing snow mass flux and saltation initiation dynamics. The more complete and accurate description of near-surface snow particle motions observable using PTV may prove useful for improving blowing snow model realism and accuracy.
\end{abstract}

\section{Introduction}

Wind transport of snow influences the variability of alpine summer runoff (Pomeroy et al., 2012; Winstral et al., 2013) is a large contributor to the growth or ablation of small mountain glaciers (Dyunin and Kotlyakov, 1980) and can contribute snow loading to avalanche-prone areas (Schweizer et al., 2003). Time-averaged blowing snow field measure- ments often present an oversimplified view of a highly variable and unsteady natural phenomenon. Physical snow trap mechanisms only provide mass flux averages over prolonged collection periods (Budd et al., 1966). Snow particle counters only recently began providing point measurements of particle speed (Nishimura et al., 2014) along with particle size and number flux values (Schmidt, 1984; Brown and Pomeroy, 1989; Kinar and Pomeroy, 2015). Snow traps and particle counters can neither measure the mechanisms of transport initiation nor provide continuous vertical profiles of particle concentration or transport. However, most current blowing snow model development has been informed from time-averaged measurements from such devices. Accordingly, simplified models of blowing snow persist in the literature that do not contain self-consistent wind-snow momentum balances, as demonstrated by Andreotti (2004) for sand. As well, there is a current lack of detailed measurements of particle-surface interactions in natural conditions.

Recent progress in blowing snow research has been accelerated by novel applications of high-speed imaging systems. Kobayashi (1972) pioneered blowing snow recordings with outdoor, $0.125 \mathrm{~s}$ shutter speed images. This was the first visual evidence of particle mechanics in the snow saltation layer and was extremely informative in the development of saltation theory (Pomeroy and Gray, 1995), but the photographs consisted of blurred snow particle streaks or were saturated with particles, disguising individual particle motions. More recently, Gordon and Taylor (2009) designed a novel and effective halogen backlit camera system to effectively obtain particle size and shape parameters in the Arctic, but they were limited to an imaging area on the order of $9 \mathrm{~mm}^{2}$. In a further study, Gordon et al. (2009) modified 
this technique to image an area of $124 \mathrm{~mm} \times 101 \mathrm{~mm}$ with a black and white binarization algorithm to obtain continuous particle density profiles. Unfortunately, particle velocity measurements were unavailable from either study.

In laboratories, several wind tunnel studies have examined drifting snow with particle image velocimetry (PIV) (Lü et al., 2012; Tominaga et al., 2012), shadowgraphy (Gromke et al., 2014), and shadowgraphic particle tracking velocimetry (PTV) (Groot Zwaaftink et al., 2014; Paterna et al., 2016), providing valuable insights into saltating snow velocity distributions, average relative wind and saltating snow velocities, particle size distributions, qualitative comparisons to transport driven by large eddy simulation, and equilibrium wind-blowing snow decoupling. Blowing snow transport model development continues to address small-scale variability (e.g., Nemoto and Nishimura, 2004; Groot Zwaaftink et al., 2014) and requires advanced measurement techniques to understand the physics driving such multiscale heterogeneities as well as evaluate the uncertainties and assumptions inherent in proposed models.

Of the multitude of blowing snow models that have been developed, many implement components of earlier aeolian saltation or initiation models, e.g., the work of Bagnold (1941), Owen (1964), Schmidt (1980), Pomeroy and Gray (1990), and Nishimura and Hunt (2000). In what follows, effort has been made to refer only to the original work containing the model component or measurement campaign under discussion, but comments generally apply to all derivatives. Following the work of Bagnold (1941), current theory often represents blowing snow in two layers, saltation and suspension, with a neglected and poorly understood creep mechanism at the lower boundary of saltation (Pomeroy and Gray, 1990; Nishimura and Hunt, 2000; Doorschot and Lehning, 2002). Once the wind surpasses a transport threshold velocity, saltating particles follow ballistic trajectories and rebound off the surface, rising no higher than $10 \mathrm{~cm}$. As wind speeds increase, saltating particles become suspended by turbulence and disperse upwards. Closely following wind streamlines, suspended particles rarely encounter the ground (Pomeroy and Male, 1992; Bintanja, 2000).

The two most commonly modeled modes of saltation initiation are "aerodynamic lift", the direct drag-induced ejections of grains, and "splash", the ejection of grains by rebounding saltating particles (Doorschot and Lehning, 2002; McElwaine et al., 2004). However, there are substantial disagreements about these mechanisms; Schmidt (1980) calculated that direct aerodynamic lift was not possible under average flow conditions over a level snow surface due to strong snow particle bonding. Doorschot et al. (2004) argued the fragile dendritic snow in their study resulted in aerodynamic lift dominance. It is likely that both mechanisms are possible and that the prevalent mechanism depends on the wind conditions and snow surface structure and cohesion. There is a growing pool of blowing snow models parameterizing these two initiation mechanisms, including the work of Doorschot and Lehning (2002), Nemoto and Nishimura (2004), and Groot Zwaaftink et al. (2014), all adapting the blowing sand initiation model of Anderson and Haff (1991) through wind tunnel measurements.

In contrast to representing saltation as a layer of particles moving with uniform trajectories (e.g., Owen, 1964) as is common in snow saltation studies (Pomeroy and Gray, 1990; Tabler, 1991; Doorschot and Lehning, 2002), recent wind tunnel studies and numerical simulations of wind transport of sand have shown the benefit of representing saltation with continuous grain velocity distribution functions (Creysells et al., 2009; Ho et al., 2012, 2014). From these observations, two populations of saltating particles are distinguishable by kinetic energy rather than by physical properties such as grain size. High-energy particles have higher and longer trajectories that are influenced by changes in wind strength. However, these particles only constitute the long tails of velocity distribution functions (Ho et al., 2012). The bulk of sand saltation observed in these studies consists of low-energy splashed "ejecta" and tractating (bed transport) grains undergoing very short hops. These grains generate the majority of mass flux and govern the mean properties of equilibrium saltation (Ho et al., 2014).

As saltation develops, transport mechanics evolve. For instance, in sand, saltation and creep transport modes are often coupled when saltation begins (Willets et al., 1991): as low-energy surface particles accelerate, they begin feeding upper regions of saltation. Allowing variability of motion in blowing snow saltation models permits consideration of additional mechanisms of saltation initiation and momentum transfer to the snow surface.

It remains unknown how well recent advances in conceptualization of blowing sand transport can improve descriptions of blowing snow because detailed observations of outdoor blowing snow particle transport processes near the snow surface have not been conducted. Perhaps due to this, current theories of snow saltation are inconsistent with each other and conceptualize a limited range of snow motions and initiation mechanisms. To improve the physical theory of blowing snow initiation and transport, this study demonstrates PTV as a tool for measuring short timescale blowing snow surface motions in an outdoor environment. The objectives of this study are to examine the mechanics of snow particle motion initiation, the detailed interactions between wind speed fluctuations and snow particle dynamics, and the role of turbulent burst mechanisms that are common in mountain environments in generating shear stress to modify snow saltation. In doing so, the potential for adapting a continuum sand transport model for describing snow saltation particle motions is assessed. 


\section{Methods}

Fieldwork was conducted during blowing snow events in March 2015 and February-March 2016 at the Fortress Mountain Snow Laboratory (FMSL), Kananaskis Valley, Alberta, Canada. FMSL receives at least $800 \mathrm{~mm}$ water equivalent of snowfall each winter, can sustain wind speeds exceeding $35 \mathrm{~m} \mathrm{~s}^{-1}$, and is home to several well-instrumented highaltitude, windswept observation sites. The blowing snow site (2000 ma.s.l.) was located in an open base area of the Fortress Mountain ski area (Fig. 1). The area was lightly used, allowing for a $350 \mathrm{~m}$ upwind fetch of undisturbed open snowfield, with the foot of a moderate ridge flanking the west $200 \mathrm{~m}$ away. The ground was snow-covered and shrub vegetation buried for the duration of the experiment with snow depths fluctuating from 60 to $120 \mathrm{~cm}$. Two Campbell Scientific CSAT3 three-dimensional ultrasonic anemometers positioned at varying heights depending on snow depth on a single mast (10-40 and 140-200 cm) measured wind speed at $50 \mathrm{~Hz}$ in three axes.

A unique aspect of this experiment was the implementation of laser-illuminated high-speed videography for outdoor nighttime snow particle tracking observations. A portable rigid frame equipped with a Megaspeed MS85K high-speed camera and a $445 \mathrm{~nm}$ wavelength $1.5 \mathrm{~W}$ continuous-wave laser was situated on the snow surface less than $1 \mathrm{~m}$ downwind from the anemometer mast (23 March 2015) or $33 \mathrm{~cm}$ away perpendicular to the flow (3 February, 3 March 2016). Dennis and Nickels (2008) suggest reasonable application of Taylor's hypothesis up to downstream distances of up to 6 times the boundary-layer depth $\delta$. While there are no measurements of $\delta$ for the present data set, it is safe to assume an extreme value of $1 \mathrm{~m}$ is less than $6 \delta$ which is often $O(10$ $100 \mathrm{~m}$ ) in the atmospheric surface layer (ASL). Thus, using Taylor's frozen turbulence hypothesis and mean wind speed of the two anemometers as a surrogate for convection velocity, the effect of the downwind separation on the representativeness of anemometer mast turbulence statistics for the actual location of snow transport is assumed negligible with lag times $<0.25 \mathrm{~s}$. Similarly, for the crosswind orientation, the size of energy containing eddies (discussed in Sect. 3), even over short recordings, are large compared to the separation. Lags between instantaneous wind and particle velocities are mentioned in the Sect. 4.

The frame was positioned on the snow surface allowing the camera a perpendicular $30 \times 140 \mathrm{~mm}$ view of the flow of saltating snow. Laser light was projected through a cylindrical lens to create a $2 \mathrm{~mm}$ wide plane orthogonal to both the snow surface and the view of the camera (Fig. 1). The light plane illuminated a 2-D projection of saltating snow particles. This allowed recordings in the lowest $5 \mathrm{~cm}$ of the atmosphere, with minimal foreground shadowing and no background reflection. PTV measurements were calculated by $\mathrm{DaVis} 8$ (LaVision) software and estimated individual snow particle velocities using tracking algorithms that

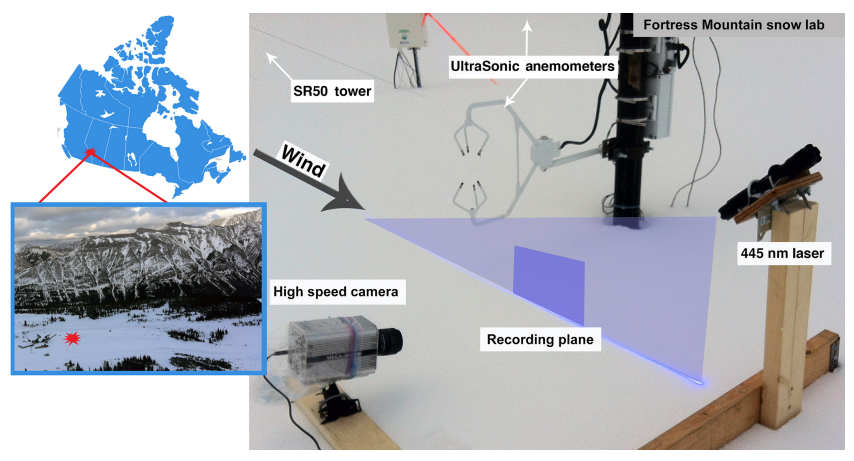

Figure 1. Blowing snow instrument setup and location of field site, Fortress Mountain Snow Laboratory, Alberta, Canada.

match discrete particles in subsequent frames imaged by the high-speed camera. Particle velocimetry techniques are normally used for wind tunnel studies (e.g., Zhang et al., 2007; Creyssels et al., 2009; Ho et al., 2011, 2012; Lü et al., 2012; Tominaga et al., 2012; Groot Zwaaftink et al., 2014; Paterna et al., 2016), with few applications, in any discipline, in an outdoor setting (e.g., Morris et al., 2007; Zhu et al., 2007; Rosi et al., 2014; Toloui et al., 2014). This is the first known application of PTV for boundary-layer blowing snow studies in a natural environment.

The high-speed saltation recordings provided a great degree of visual distinction of surface particle motion and the use of 2-D laser illumination minimized particle overlap (e.g., Kobayashi, 1972). As the camera was focused close to the snow surface, hundreds of thousands of rebound and splash events were recorded over the winter field seasons. In addition to PTV, videos were later reviewed with playback reduced 40-70 times, providing qualitative insight to the mechanics of near-surface saltating particle motion and bed interactions.

Figure 2 displays an example of velocity vectors calculated from $1 \mathrm{~s}$ of 23 March 2015 (recording no. 3). The stationary snow surface was masked out. The dashed black line indicates the height $\left(h_{0}\right)$ of the upper limit of particles whose velocities were heavily influenced by surface microtopography and contributed uncharacteristic velocity and concentration profile statistics. In order to account for gradual changes in surface topography, an orthogonal terrain-following coordinate system, in which $y=0$ is always at the snow surface and the $y$ direction is parallel to gravity, was adopted to calculate vertical profiles of mean projected horizontal particle velocity $u_{\mathrm{p}}$ and particle number flux concentrations $F_{z}$ :

$F_{z}=\frac{n(z)^{*} u_{\mathrm{p}}(z)}{\sum_{z}\left(n(z)^{*} u_{\mathrm{p}}(z)\right)}$,

where $n(z)$ is the number of particles identified at height $z$. This allowed a consistent reference frame along subtle inclines like that found in Fig. 2. Immersed boundary coordinates based on the camera frame $\left(x_{\mathrm{f}}, y_{\mathrm{f}}\right)$ are not represen- 


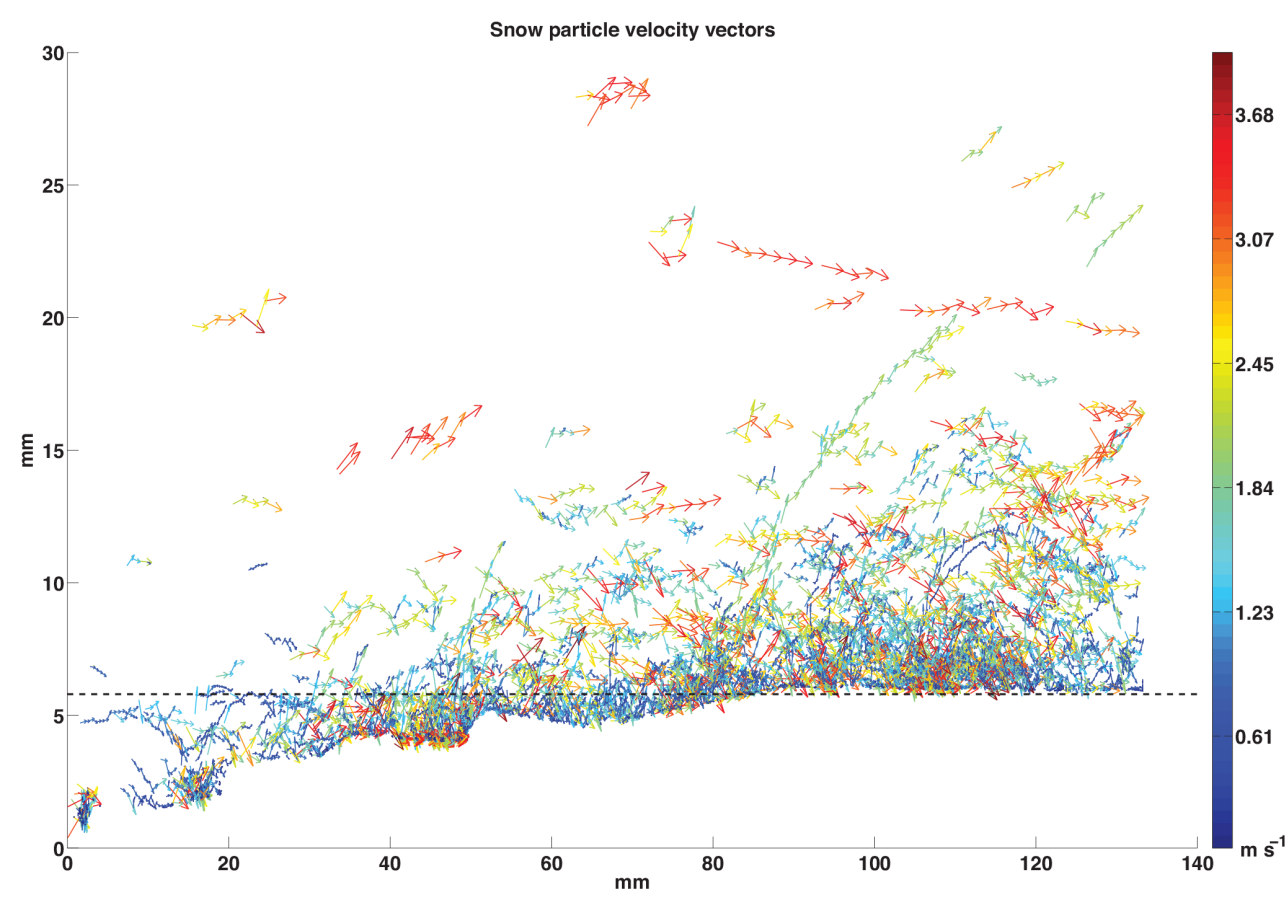

Figure 2. Sparse snow particle velocity vector field during $1 \mathrm{~s}$ of recording on 23 March, vector colors scaled according to total particle speed. The dashed line shows reference below which particles are influenced by microtopography.

tative of height above the complex surface (e.g., $\left(x_{\mathrm{f}}, y_{\mathrm{f}}\right)=$ $(5,100)$ is below the surface whereas $\left(x_{\mathrm{f}}, y_{\mathrm{f}}\right)=(1,5)$ is above the snow) and caused statistical values to become increasingly dubious as one approaches the roughness layer. This can result in misrepresenting surface fluxes. For example, immersed boundary coordinates indicate a flux maximum of $7 \mathrm{~mm}$ for Fig. 2 because of the lack of vectors present below this height on the right side of the frame. Additionally, the height of surface microtopography varied as recordings were made over hours of active erosion and deposition, changing the surface structure and subsequently the relative height of measurements with an immersed coordinate system. Terrain-following coordinates allowed observations to be made over a natural snowpack, crucial for improving the realism of blowing snow measurements, while still accurately defining the near-surface region.

The improved realism afforded by PTV over a natural snowpack in the ASL was counterbalanced by increased difficulty in obtaining valuable data from this methodology and from sonic anemometry during blowing snow storms. Ultrasonic wind speed measurements sometimes included spikes, "NaN" readings or were flagged for skewness/kurtosis (Vickers and Marht, 1997); these concurrent video recordings were used only for qualitative comparison. Spanwise fluctuations in wind caused snow particles to travel transverse to the plane of light, and the streamwise wind direction usually varied at the blowing snow site over the course of an evening's observations. PTV relies on particles to remain in the plane of light for illumination and tracking through multiple frames. While the frame could be adjusted for slow variations in wind direction, directional variations during wind gusts were a significant complication. To reduce particle mismatch errors and improve velocity calculation accuracy, initial visual quality controls were implemented, discarding video that contained particles obviously moving transverse to the plane of light.

Post-processing required individual particles to be evident in at least five subsequent frames and limitations were imposed on velocity vector tracks to discard physically unrealistic acceleration or direction change from one frame to the next. The camera depth of field and light plane thickness limited out-of-plane particle velocity components to $\pm 0.5 \mathrm{~m} \mathrm{~s}^{-1}$. Further uncertainty derives from the limited ability of PTV software to match individual snow particles at high wind speeds $\left(>9 \mathrm{~m} \mathrm{~s}^{-1}\right.$ at $40 \mathrm{~cm}$ height). The particle matching interrogation area becomes larger as wind speeds increase and particles travel further from one frame to the next. This exponentially increases the number of particles that may be incorrectly matched.

To verify particle enumeration, a dual-threshold black and white binarization technique adapted from Otsu (1979) was used to estimate particle concentration in each frame. This complimentary method of particle identification used algorithms that, unlike PTV, are not affected by transverse particle motion or particle matching limitations in gusty conditions. Binarization estimates of blowing snow concentration profiles were in sufficient agreement with concentration profiles generated by PTV, lending confidence to the measurements of particle trajectories. Additionally, with the binary 
Table 1. Descriptions of the snowpack for each night of recording including a description of the condition of the snow surface and concurrent precipitation, bulk density of the top $5 \mathrm{~cm}$ of grains, mean air temperature at the upper anemometer, snow surface temperature, hand surface hardness, and hand hardness index (HHI) values following Fierz et al. (2009), as well as snow grain size as determined from the blowing snow video. ${ }^{*}$ Density and snow surface temperature not available on 23 March with density estimated from Pruppacher and Klett (1997).

\begin{tabular}{|c|c|c|c|c|c|}
\hline Date & $\begin{array}{l}\text { Snow surface } \\
\text { conditions and } \\
\text { weather }\end{array}$ & $\begin{array}{r}\text { Density of loose } \\
\text { surface grains }\end{array}$ & $\begin{array}{r}2 \mathrm{~m} \text { air/snow } \\
\text { surface } \\
\text { temperature }\end{array}$ & $\begin{array}{r}\text { Surface hardness } \\
(\mathrm{HHI})\end{array}$ & $\begin{array}{r}\text { Blowing snow } \\
\text { grain size } \\
(\mu \mathrm{m})\end{array}$ \\
\hline 23 March & $\begin{array}{l}5 \mathrm{~cm} \text { graupel over old } \\
\text { snow with light flurries }\end{array}$ & $\sim 350^{*}\left(\mathrm{~kg} \mathrm{~m}^{-3}\right)$ & $-1^{\circ} \mathrm{C} /(-)^{*}$ & $\begin{array}{l}\text { Fist over melt-freeze crust } \\
(1-4)\end{array}$ & $\begin{array}{r}263 \\
\text { (Max: 1200) }\end{array}$ \\
\hline 3 February & $\begin{array}{l}\text { Fine decomposing grains } \\
\text { on wind slab/sastrugi } \\
\text { No precipitation }\end{array}$ & $228\left(\mathrm{~kg} \mathrm{~m}^{-3}\right)$ & $-10^{\circ} \mathrm{C} /-10^{\circ} \mathrm{C}$ & $\begin{array}{r}1 \text { Finger-pencil } \\
(3-4)\end{array}$ & $\begin{array}{r}258 \\
(\operatorname{Max}: 850)\end{array}$ \\
\hline 3 March & $\begin{array}{l}\text { Fresh snow. } \\
\text { No precipitation }\end{array}$ & $156\left(\mathrm{~kg} \mathrm{~m}^{-3}\right)$ & $-2^{\circ} \mathrm{C} /-5^{\circ} \mathrm{C}$ & $\begin{array}{r}\text { Fist } \\
(1)\end{array}$ & $\begin{array}{r}276 \\
\text { (Max: 2500) }\end{array}$ \\
\hline
\end{tabular}

image and PTV time series, it was possible to use a flood-fill algorithm to identify the connected components of blowing snow particles. Making an assumption of grain sphericity and constant density $\left(917 \mathrm{~kg} \mathrm{~m}^{-3}\right)$ and using instantaneous mean particle velocities, the equivalent diameters of the particles were used to estimate blowing snow volume fractions and instantaneous density flux $Q_{\mathrm{s}}\left(\mathrm{kg} \mathrm{m}^{-2} \mathrm{~s}^{-1}\right)$. Particle diameter measurements generated gamma distributions of particle size (Fig. 3) consistent with other blowing snow literature (Budd, 1966; Schmidt, 1982).

PTV measurements in exceptionally high wind speeds $\left(>10 \mathrm{~m} \mathrm{~s}^{-1}\right)$ were not possible because the laser light became blocked by particles. Therefore the data set used in this analysis is focused on observations taken during relatively low mean wind speeds for blowing snow (mean 4-7 $\mathrm{m} \mathrm{s}^{-1}$, Table 2); these sometimes included periods of intermittent turbulent bursts and intermittent snow transport. After all post-processing, three nights of recording satisfied all quality controls requirements. This included 12 recordings spanning $266 \mathrm{~s}$ of raw video and 470000 frames.

\section{Results}

Examination of data calculated from 23 March 2015, 3 February 2016, and 3 March 2016 demonstrated the value of PTV measurements over varying wind speeds during periods of natural variation in saltating grain shape, type, and size. Descriptions of the snowpacks following the designations of the International Classification for Seasonal Snow on the Ground (Fierz et al., 2009) for each night can be found in Table 1, with particle size gamma distributions for each recording in Fig. 3. Sample videos from each night can also be found in the Supplement. During all three nights, transport was highly intermittent, implying wind speeds were near threshold conditions. This was a necessary condition for ac-

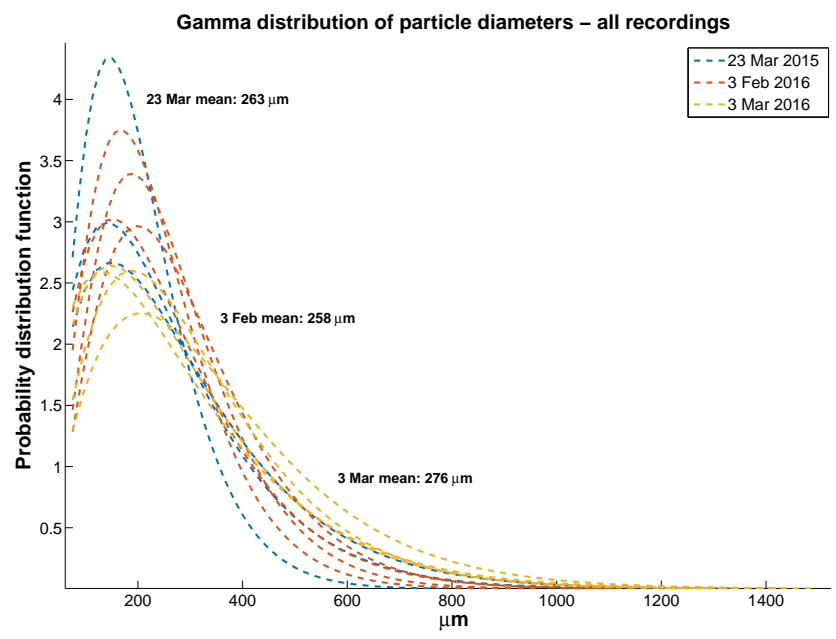

Figure 3. Two-parameter Gamma distributions of particle diameters from each recording. Diameter measurements were obtained through black and white video binarization and equivalent diameter calculations of flood-fill identified connected components.

curate particle tracking in aeolian systems as images can become easily saturated (Ho et al., 2014).

\subsection{Wind characteristics}

Near-neutral (slightly stable) stability conditions were found during all nights using flux- and gradient-based methods (Figs. S1-S3 in the Supplement); however, steady-state wind conditions $\left(\frac{\partial U}{\partial t}=0\right)$ did not occur during the field campaign. The less strict steady-state requirements of Foken and Wichura (1996) were also tested to further confirm steady-state conditions were not evident. Recording and wind characteristics encompassing the three nights are displayed in Table 2. Mean wind speed $\bar{u}$, friction velocity $u_{*}^{2}=\left[{\overline{u^{\prime} w^{\prime}}}^{2}+{\overline{v^{\prime} w^{\prime}}}^{2}\right]^{1 / 2}$ (Stull, 1988), and covariance-based 
Table 2. Wind characteristics: mean wind speed $\bar{u}$, friction velocity $u_{*}$, aerodynamic roughness height $z_{0}$, turbulence intensity $I$, and Shields parameter $S$ for recordings on 23 March 2015, 3 February, and 3 March 2016. Average values from the 15 min surrounding each recording (and recording-only period in parentheses) are shown for the two measurement heights. Estimates of blowing snow flux $Q_{\mathrm{s}}$ in $\mathrm{kg} \mathrm{m}^{-2} \mathrm{~s}^{-1}$ are included for recording only periods.

\begin{tabular}{|c|c|c|c|c|c|c|c|}
\hline Recording & Duration/frames & $\mathrm{ms}^{-1}$ & $\mathrm{~ms}^{u_{*}}$ & $\begin{array}{r}z_{0} \\
\mathrm{~mm}\end{array}$ & $\begin{array}{l}I \\
\%\end{array}$ & $\begin{array}{r}S \\
\text { non-dim }\end{array}$ & $\mathrm{kg} \mathrm{m}^{-2} \mathrm{~s}_{\mathrm{s}}{ }^{-1}$ \\
\hline 23/3/15 no. 1 & $7.3 \mathrm{~s} / 9147$ & & & & & & 0.0146 \\
\hline $200 \mathrm{~cm}$ & & $1.2(5.5)$ & $0.61(0.23)$ & $910.1(0.1)$ & $1.10(0.22)$ & $0.169(0.028)$ & \\
\hline $40 \mathrm{~cm}$ & & $1.1(4.7)$ & $0.46(0.26)$ & $126.9(0.3)$ & $1.13(0.27)$ & $0.096(0.034)$ & \\
\hline $23 / 3 / 15$ no. 2 & $11.4 \mathrm{~s} / 14299$ & & & & & & $2.54 \times 10^{-4}$ \\
\hline $200 \mathrm{~cm}$ & & $1.9(4.3)$ & $0.48(0.22)$ & $410.6(0.8)$ & $1.04(0.24)$ & $0.139(0.039)$ & \\
\hline $40 \mathrm{~cm}$ & & $1.7(4.2)$ & $0.40(0.08)$ & $69.9\left(1.3 \times 10^{-4}\right)$ & $1.04(0.16)$ & $0.096(0.007)$ & \\
\hline $23 / 3 / 15$ no. 3 & $13.1 \mathrm{~s} / 16404$ & & & & & & 0.0237 \\
\hline $200 \mathrm{~cm}$ & & $1.4(5.3)$ & $0.28(0.55)$ & $312.2(42.4)$ & $0.80(0.40)$ & $0.037(0.148)$ & \\
\hline $40 \mathrm{~cm}$ & & $1.3(4.8)$ & $0.24(0.57)$ & $116.5(8.0)$ & $0.79(0.45)$ & $0.027(0.122)$ & \\
\hline $3 / 2 / 16$ no. 1 & $27.8 \mathrm{~s} / 43075$ & & & & & & 0.0179 \\
\hline $155 \mathrm{~cm}$ & & $4.67(5.78)$ & $0.27(0.26)$ & $1.7(0.3)$ & $0.39(0.22)$ & $0.038(0.036)$ & \\
\hline $25 \mathrm{~cm}$ & & $3.96(4.9)$ & $0.29(0.22)$ & $1.6(0.06)$ & $0.41(0.21)$ & $0.044(0.026)$ & \\
\hline $3 / 2 / 16$ no. 2 & $28.0 \mathrm{~s} / 57487$ & & & & & & 0.0375 \\
\hline $155 \mathrm{~cm}$ & & $3.91(5.35)$ & $0.22(0.23)$ & $1.8(0.4)$ & $0.45(0.23)$ & $0.025(0.027)$ & \\
\hline $25 \mathrm{~cm}$ & & $3.33(4.54)$ & $0.22(0.27)$ & $1.0(0.2)$ & $0.46(0.25)$ & $0.025(0.037)$ & \\
\hline $3 / 2 / 16$ no. 3 & $28.1 \mathrm{~s} / 57528$ & & & & & & 0.0547 \\
\hline $155 \mathrm{~cm}$ & & $4.3(5.7)$ & $0.34(0.45)$ & $12.2(12.5)$ & $0.44(0.27)$ & $0.054(0.106)$ & \\
\hline $25 \mathrm{~cm}$ & & $3.67(4.7)$ & $0.27(0.3)$ & $1.7(0.7)$ & $0.44(0.27)$ & $0.034(0.045)$ & \\
\hline 3/2/16 no. 4 & $28.0 \mathrm{~s} / 57409$ & & & & & & 0.044 \\
\hline $155 \mathrm{~cm}$ & & $3.1(6.94)$ & $0.31(0.33)$ & $35.4(0.4)$ & $0.83(0.17)$ & $0.056(0.055)$ & \\
\hline $25 \mathrm{~cm}$ & & $2.6(5.66)$ & $0.31(0.33)$ & $14.7(0.4)$ & $0.84(0.2)$ & $0.056(0.055)$ & \\
\hline $3 / 3 / 16$ no. 1 & $27.9 \mathrm{~s} / 43182$ & & & & & & 0.0046 \\
\hline $140 \mathrm{~cm}$ & & $5.33(4.58)$ & $0.30(0.16)$ & $1.7(0.03)$ & $0.28(0.16)$ & $0.035(0.013)$ & \\
\hline $10 \mathrm{~cm}$ & & $4.3(3.75)$ & $0.23(0.21)$ & $0.2(0.3)$ & $0.29(0.19)$ & $0.021(0.021)$ & \\
\hline $3 / 3 / 16$ no. 2 & $27.9 \mathrm{~s} / 43182$ & & & & & & 0.1474 \\
\hline $140 \mathrm{~cm}$ & & $4.33(5.47)$ & $0.25(0.42)$ & $1.8(10)$ & $0.3(0.23)$ & $0.030(0.084)$ & \\
\hline $10 \mathrm{~cm}$ & & $3.57(4.33)$ & $0.20(0.26)$ & $0.3(0.1)$ & $0.3(0.23)$ & $0.019(0.033)$ & \\
\hline 3/3/16 no. 3 & $27.9 \mathrm{~s} / 43182$ & & & & & & 0.1561 \\
\hline $140 \mathrm{~cm}$ & & $4.7(5.5)$ & $0.27(0.23)$ & $2(0.04)$ & $0.26(0.16)$ & $0.035(0.02)$ & \\
\hline $10 \mathrm{~cm}$ & & 3.85 (4.6) & $0.22(0.20)$ & $0.4(0.1)$ & $0.27(0.18)$ & $0.023(0.026)$ & \\
\hline $3 / 3 / 16$ no. 4 & $28.1 \mathrm{~s} / 57528$ & & & & & & 0.0542 \\
\hline $140 \mathrm{~cm}$ & & $4.6(5.54)$ & $0.58(0.24)$ & $82(0.2)$ & $0.53(0.17)$ & $0.149(0.028)$ & \\
\hline $10 \mathrm{~cm}$ & & $3.7(4.35)$ & $0.45(0.21)$ & $15(0.9)$ & $0.54(0.2)$ & $0.09(0.021)$ & \\
\hline $3 / 3 / 16$ no. 5 & $28.1 \mathrm{~s} / 57528$ & & & & & & 0.3467 \\
\hline $140 \mathrm{~cm}$ & & $4.3(6.06)$ & $0.50(0.31)$ & $63(0.8)$ & $0.61(0.36)$ & $0.131(0.046)$ & \\
\hline $10 \mathrm{~cm}$ & & $3.5(4.73)$ & $0.42(0.35)$ & $14(2)$ & $0.63(0.4)$ & $0.092(0.06)$ & \\
\hline
\end{tabular}

roughness length $z_{0}=z e^{-0.4 \bar{u} / u_{*}}$, calculated over $15 \mathrm{~min}$ periods surrounding recordings as well as solely the recording time, are shown for both anemometer measurements as they are the parameters most often used in blowing snow models. Additional values of turbulence intensity $I=\sqrt{\overline{u^{\prime 2}}+\overline{v^{\prime 2}}}+\overline{w^{\prime 2}} / \sqrt{\overline{u^{2}}+\overline{v^{2}}+\overline{w^{2}}}$ and Shields number
$S=\rho_{\text {air }} u_{*}^{2} / \rho_{\text {ice }} g d$ (based on mean particle size for each video) over both time periods are provided, as well as mean blowing snow flux $\left(Q_{\mathrm{s}} \mathrm{kg} \mathrm{m}^{-2} \mathrm{~s}^{-1}\right)$ for the recordings.

If wind measurements are close to the surface, such as during the 3 March 2016 recordings, the physical path length of the sonic anemometers can result in losses of high- 
frequency turbulence. Following the guidelines of van Boxel et al. (2004), the Nyquist frequency $(25 \mathrm{~Hz})$ is a limiting factor for mean wind speeds greater than $3 \mathrm{~m} \mathrm{~s}^{-1}$, and may also contribute to some discrepancy of low and upper anemometer turbulence measurements. Additionally, the lower anemometer measurements during recording no. 2 on 23 March 2015 appears to have been contaminated as there is a significant change in covariance derived $u_{*}$ and $z_{0}$ values between the two heights.

The ASL fit a Prandtl-von Kármán logarithmic-law profile poorly during the storms, most likely due to violations of horizontally homogeneous and flat terrain and stationarity requirements. Recording period log-law-based roughness lengths $z_{0}=e^{\frac{u_{1} \ln \left(z_{2}\right)-u_{2} \ln \left(z_{1}\right)}{u_{1}-u_{2}}}$ and friction velocities $u_{*}=\frac{\kappa \bar{u}(z)}{\ln \left(z / z_{0}\right)}$ were loosely comparable to lower anemometer fluctuation-based measurements with $z_{0}$ errors less than $\pm 100 \%$ (except 3 March no. 9), and $u_{*}$ errors less than $\pm 70 \%$, often slightly underestimating.

The 15 min roughness lengths that were generated by covariance methods resulted in inaccurate log-linear wind profiles that indicated a zero velocity zone for the wind well above the snow saltation layer and often at extremes values of tens to hundreds of $\mathrm{mm}$ (Table 2). High roughness lengths appear characteristic of this mountain region. At a nearby site $14 \mathrm{~km}$ northeast and $600 \mathrm{~m}$ lower in elevation, Helgason and Pomeroy (2005) attributed similar large covariance derived $z_{0}$ values at varying heights to the effects of surrounding topography and the nonstationary and non-steady-state nature of the wind. The modified "focal-point" log-linear wind profile proposed by Bagnold (1941) for aeolian transport was not recognized in this study, with estimates of focal lengths fluctuating from several $\mathrm{mm}$ up to $6 \mathrm{~m}$.

The wind was characterized by brief moments of intense gusting separated by periods of relatively calm conditions as also noted at the Helgason and Pomeroy (2005) research site. 15 min turbulence intensity ranged from 26 to $113 \%$, consistently higher than the recording period values where short time series preclude larger fluctuations around mean values. As a result, values of $\bar{u}, u_{*}$, and $z_{0}$ consistently differ between video recording-averaged (7.3-28s) and $15 \mathrm{~min}$ averaged values. Turbulent gust-driven snow transport events dominated the nights. Eleven out of $1215 \mathrm{~min}$ averages present lower wind speeds than the recording period with the long averages often below thresholds of transport.

Figure 4 shows varying Reynolds stress $(\mathrm{RS}=u w)$ generation during recording specific periods following the language of quadrant hole analysis (Willmarth and Lu, 1972). Sweep and ejection events (Q2 and Q4) often contributed the majority of RS at both anemometers, with a more pronounced role closer to the ground, indicating changes in the snow surface influence on wind mechanics. Q2 and Q4 stress also occupied a disproportionately small amount of time near the surface, as can be seen in the impact factors inset in the bar graphs $(\mathrm{IF}=(\%$ Reynolds stress $) /(\%$ time $))$ that are greater than unity. Therefore, when strong events are captured during the recordings, RS values can be much larger than long time averages. The presence of a single pronounced sweep event in recording no. 3, 23 March (discussed in Sect. 3.3) contributed to a high recording period turbulence intensity (40-45\%) and a much higher recording friction velocity than the $15 \mathrm{~min}$ values $\left(0.48\right.$ and $0.24 \mathrm{~m} \mathrm{~s}^{-1}$ respectively) and will be discussed in detail in Sect. 3.3.

Understanding the changes in the quadrants generating RS helps illuminate the differences in $u_{*}$ values at the two measurement heights over these short recording timescales. The recordings with the largest discrepancy in $u_{*}$ (besides 23 March no. 2, where low height wind measurements are questionable) are 3 February no. $3\left(u_{*}=\{0.30,0.45\} \mathrm{ms}^{-1}\right)$ and 3 March no. $2\left(u_{*}=\{0.26,0.43\} \mathrm{ms}^{-1}\right)$. This was the result of a significant decrease in the magnitude of mean RS at the lower measurements $\left(0.27\right.$ vs. $0.11 \mathrm{~m}^{2} \mathrm{~s}^{-2}$ and $0.22 \mathrm{vs}$. $0.09 \mathrm{~m}^{2} \mathrm{~s}^{-2}, 3$ February and 3 March respectively), while the turbulence intensity remained nearly constant (Table 2). The reduced presence of Q1 and Q3 at the lower heights and increased impact factor of Q2 and Q4 (Fig. 4) indicated a complex shift in boundary-layer dynamics towards the snow surface that is beyond the scope of this paper. Other recordings exhibited much closer friction velocity and roughness length values at the two anemometers, indicating similar turbulent motions were captured.

As also seen by Bauer et al. (1998), sweeps and ejections did not immediately follow one another; rather there were prolonged clusters of sweeps and ejections with gaps in between (Fig. 5a). The gaps may be a result of point measurements' inability to capture a full 3-D motion (Bauer et al., 1998), but nevertheless the measurements showed a significantly different RS generation than that typically found in wind tunnels. For example, Fig. 5a and b compare RS values in a recent blowing snow wind tunnel experiment of Paterna et al. (2016) with RS found on 3 February 2016 at FMSL at similar friction velocities $\left(0.25\right.$ and $0.27 \mathrm{~m} \mathrm{~s}^{-1}$ respectively). A sweep signal of magnitude greater than 1 standard deviation of RS is indicated above the given RS time series by a blue triangle, while similar ejections are marked by brown triangles. Visually, there is a noticeable shift toward clustered sweep and ejection events at FMSL (Fig. 5a), in which clustered pockets of sweeps alternated with ejections, while the sweep-ejection cycle and turbulent energy occurred at much a higher frequency in wind-tunnel-based measurements by Paterna et al. (2016) (Fig. 5b). This is further confirmed in the power spectral density plots of streamwise wind speed (Fig. 5c) and in the discussion by Paterna et al. (2016). Reconciling these differences between motions in atmospheric boundary layers and wind tunnel flows is challenging (Hutchins et al., 2012) and the substantial differences in Reynolds number must be kept in mind when comparing blowing snow studies in wind tunnel and outdoor environments. 



Figure 4. Percentage of Reynolds stress distributed by quadrants analysis during 12 blowing snow recordings with impact factor (\% stress / \% time) inset in Q2 and Q4 events. Note dominance of Q2 and Q4 generated stress. For 23 March - no. 2, the low anemometer measurement are contaminated.


Figure 5. Plots (a) and (b) compare Reynolds shear stress signals from 3 February 2016 and Paterna et al. (2016) wind tunnel blowing snow studies. Triangles indicated sweep and ejection events larger than 1 standard deviation of Reynolds stress. (c) Normalized power spectral density for streamwise velocity for the two time series. 

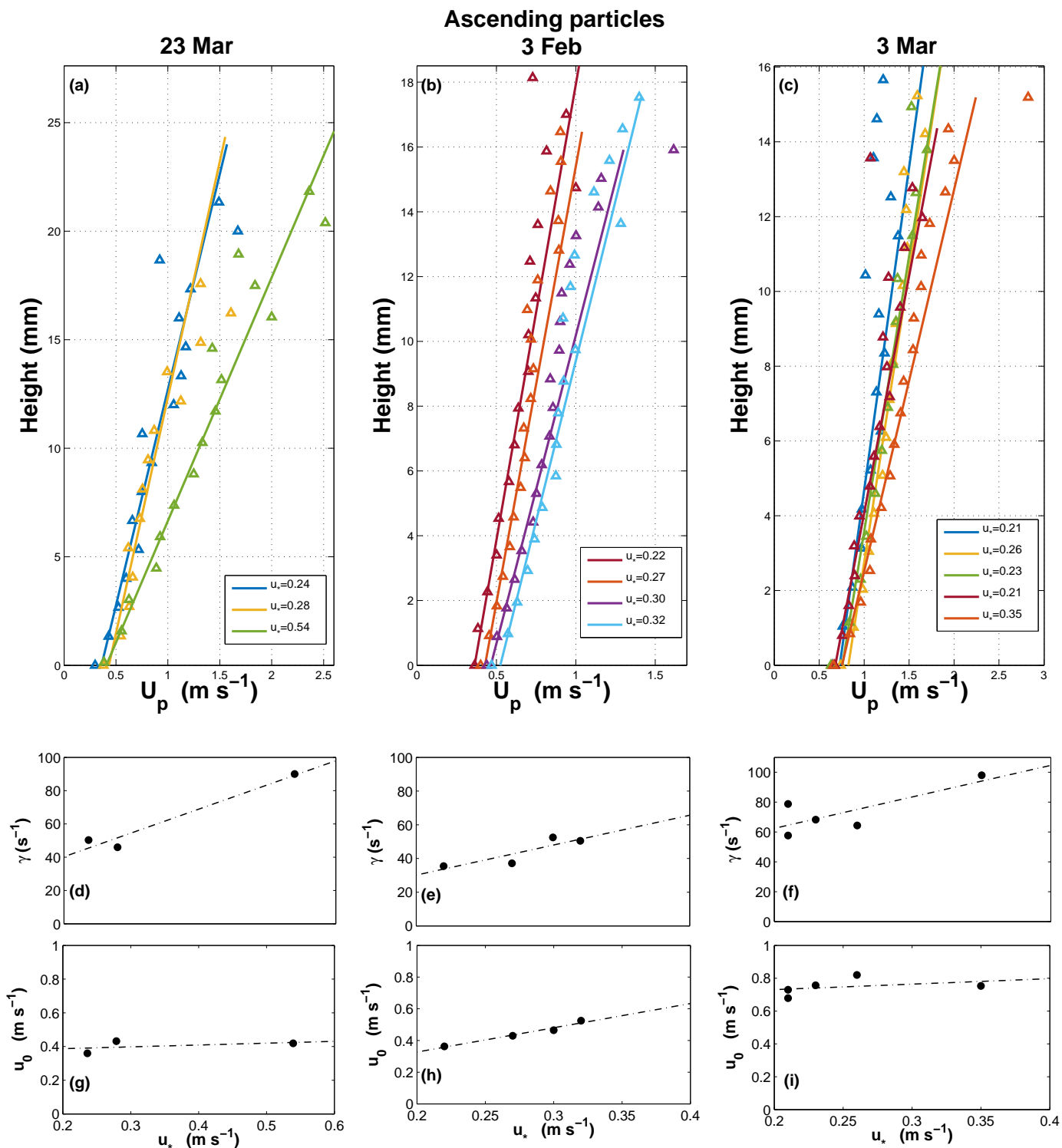

Figure 6. (a-c) Average ascending snow particle horizontal velocities in lower saltation layer (triangles) with best-fit linear profile for the first $10 \mathrm{~mm} . u_{*}$ values are calculated from 200, 25, and $10 \mathrm{~cm}$ for 23 March, 3 February, and 3 March respectively. (d-f) Friction velocity vs. particle velocity gradient $(\gamma)$ for each recording. $(\mathbf{g}-\mathbf{i})$ Friction velocity vs. particle slip velocity $\left(u_{0}\right)$ for each recording.

\subsection{Vertical PTV profiles}

Figure 6 shows profiles of ascending particle horizontal velocity for the three nights of recording with linear regressions based on the lower $10 \mathrm{~mm}$. Profiles were designated by their recording-specific low anemometer $u_{*}$ values except for 23 March, when the lower wind measurements for recording no. 2 were contaminated. Thus, all 23 March recordings were compared using $2 \mathrm{~m}$ wind.

Particle motions begin with an initial ejection velocity at the surface and then accelerate due to fluid drag in the wind. Therefore the height of an ascending saltating particle should be a function of the time spent accelerating. The profiles of horizontal velocities of ascending particles confirmed this acceleration in Fig. 6. The average momentum transfer from wind to grain was estimated from the inverse slope of the plots and indicated the ability of the wind to entrain and accelerate particles. For all three nights there is a near constant particle velocity gradient immediately above the surface, $\left(\frac{\partial u_{\mathrm{p}}}{\partial z}=\gamma, \gamma \in \mathbb{R}^{+}\right)$. Above $\sim 8-12 \mathrm{~mm}$, depending on the night, mean particle velocities deviate from the linear profile as seen in Fig. 6 and confirmed by normalized root mean square error (NRMSE) changes from the order of 0.01 to 0.1 above and below $10 \mathrm{~mm}$ respectively. It must be noted that this did not indicate a discrete transition height from creep to saltation but is rather evidence of a continuous spec- 
trum of particle velocities (Anderson, 1987; Ho et al., 2012) transitioning to a higher energy population away from the surface. As these recordings captured intermittent transport, saltation is in constant readjustment to the turbulent wind, with particles falling in and out of the higher levels of saltation (discussed further in Sect. 3.3). This prevented a consistent adherence to the linear profile as seen by Ho et al. (2011), though both studies found linear profiles overestimate particle velocity at greater heights.

The velocity gradient (shear rate) $\gamma$ was estimated by linear regression and varied from 35 to $98 \mathrm{~s}^{-1}$. Variations in wind speed and $Q_{\mathrm{s}}$ during each recording period indicate blowing snow transport never attained equilibrium. However, $\gamma$ values are comparable to wind tunnel PTV sand velocity gradients $\left(39.0-150 \mathrm{~s}^{-1}\right)$ measured below $30 \mathrm{~mm}$ by Zhang et al. (2007) and the range of $20-60 \mathrm{~s}^{-1}$ found by Ho et al. (2011). For each night, $\gamma$ increases with increasing friction velocity (Fig. 6d, e, f). The Ho et al. (2011) rigid bed experiments were conducted at comparable Shields numbers to the high hand hardness index (HHI), wind-hardened 3 February experiments (Ho et al., 2011: [0.013, 0.043]; this study: $[0.026,0.061]$ ) and shared several trends discussed here and below. For example, as for Ho et al. (2011), the night of 3 February had on average the lowest $\gamma$ values (mean $44 \mathrm{~s}^{-1}$ vs. $69 \mathrm{~s}^{-1}$ for the erodible beds) and the least variation in $\gamma$ though transport occurred during comparable friction velocities, as well as higher Shields parameters than many 23 March and 3 March recordings (Table 2). The erodible bed studies were performed at consistently higher Shields parameters for the Ho experiments (Ho et al., 2011: [0.07, 0.14], Aksamit and Pomeroy: [0.01, 0.12]), yet both studies also found increases in $\gamma$ with friction velocity for the erodible beds. Ho et al. (2011) found less variance in $\gamma$ over all friction velocities as could be expected from consistent equilibrium conditions.

As with wind tunnel sand studies (Zhang et al., 2007; Creyssels et al., 2009; Ho et al., 2011), large nonzero particle slip velocities were observed. The influence of surface microtopography and density of the flow prevented an exact measurement of particle slip velocity $u_{0}$, because it becomes difficult to enumerate all grains at the surface (Creyssels et al., 2009). However, by extrapolating the linear regression plots of constant shear rate $\mathrm{d} u_{\mathrm{p}} / \mathrm{d} z=\gamma$ one can estimate $u_{0}$. As found in the same Ho study, our 3 February "rigid bed" experiments exhibited a nearly linear increase in $u_{0}$ with $u_{*}$ (Fig. 6h). While our $u_{0}$ measurements had a larger range for the "erodible bed" nights of 23 March 2015 and 3 March 2016 (Fig. 6g, i) than that of Ho et al. (2011) and Creyssels et al. (2009), who found a near constant slip velocity, no definitive trend with $u_{*}$ could be identified either. A purely constant slip velocity over erodible beds most likely depends on equilibrium transport conditions as has been theoretically explained by Ungar and Haff (1987) and may explain the ambiguity in these results.
Figure 7 shows the vertical profile of the normalized particle number flux calculated as Eq. (1). A normalized number flux profile was chosen instead of the volume fraction (e.g., Ho et al., 2011) or mass flux density profile (Creyssels et al., 2009) because of computational limitations of the PTV package in DaVis 8 and the nonequilibrium transport during the recordings. Since it is impossible to control the rate of transport in nature, and volume fractions will change with rates of transport, wind fluctuations, and snow surface conditions, it was informative to compare number flux concentrations between periods of diverse mass transport to determine differing transport mechanics over varying snow and wind conditions. As the study was focused on the dynamic role of surface transport, and not measuring mass flux, each concentration profile was renormalized by the amount of flux that occurred during a recording to compare what proportion of total particle transport occurs at each height at suggested by Ellis et al. (2009) for aeolian transport profiles in nature. This allowed observation of changes in the relative importance of regions of transport.

The fractional number flux fits an exponential decrease of the form $v(z)=v_{0} \exp \left(-z / l_{\mathrm{v}}\right)$ with increasing accuracy as one approaches the densest flow at the surface, similar to sand and snow saltation profiles seen elsewhere (e.g., Maeno et al., 1980; Nishimura and Hunt, 2000; Creyssels et al., 2009; Ellis et al., 2009; Ho et al., 2011; Lü et al., 2012), with $v_{0}$ and $l_{\mathrm{v}}$ being fitted parameters, the latter referred to as the decay length. The number flux decay length $l_{\mathrm{v}}$ indicated how quickly the number flux concentration approached zero (Fig. $7 \mathrm{~d}, \mathrm{e}, \mathrm{f}$ ), but because there were large variations in the surface concentration $v_{0}$ in the present study, more consistent trends can be observed with the momentum deficit height $h_{\mathrm{v}}$, the height below which $75 \%$ of particle flux occurred. As seen in the right inset of Fig. 7, there is a nonlinear increasing relationship between friction velocity and $h_{\mathrm{v}}$ for the 3 February and 3 March recordings. After disregarding 23 March (discussed below), values of $h_{\mathrm{v}}$ followed an approximate power law relationship $\left(a u_{*}^{\mathrm{b}}+c, R^{2}=0.77\right)$ with asymptotic-like behavior towards the top of the region of interest $(\sim 11 \mathrm{~mm})$. At low friction velocities, near-surface saltation was dominated by transport below $7 \mathrm{~mm}$, with transport becoming gradually more uniform as $h_{\mathrm{v}}$ approached the top of the camera frame at higher friction velocities.

23 March exhibited very little change in $h_{\mathrm{v}}$ and $v_{0}$ with only a slight decrease in $l_{\mathrm{v}}$. Thus, concentration was largely invariant with wind strength. This is remarkably similar to the erodible bed findings of Ho et al. (2011). Only one recording had comparable Shields numbers to Ho, but the noncohesive graupel bed and spherical snow grains most similarly represented sand grains and an erodible sand bed out of the three nights.

The near-surface location of the maximum of $F_{z}$ found over all recordings in Fig. 7 is in disagreement with models using Bagnold's focal height (Bagnold, 1941) to predict a peak mass flux at some distinct height above the sur- 

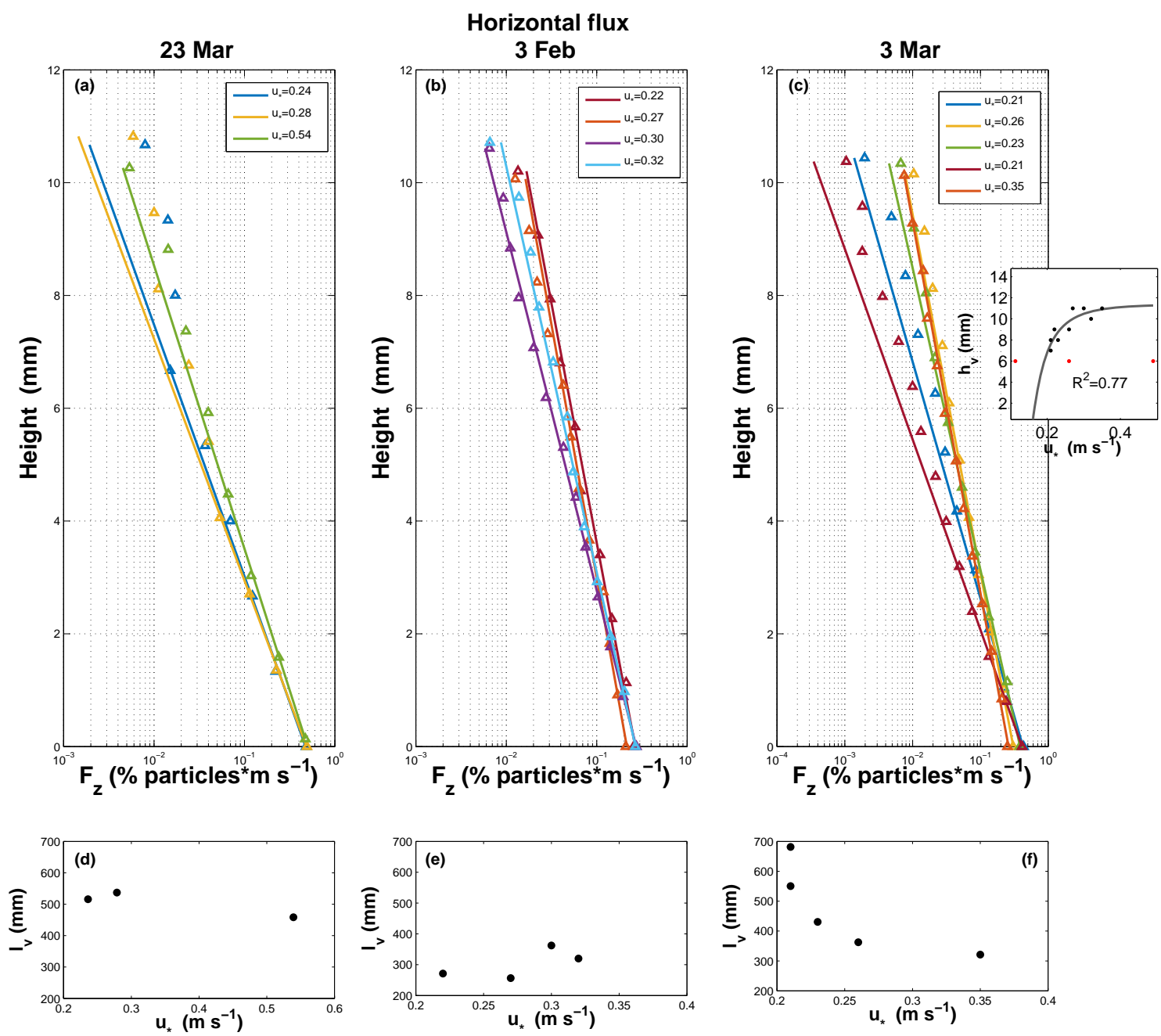

Figure 7. Plots (a-c) are mean horizontal flux measurements $\left(F_{z}\right)$ and best-fit exponential decay. Plots (d-f) are friction velocity vs. decay length for each night. Friction velocity vs. $h_{\mathrm{v}}$ (height below which $75 \%$ number flux occurred) for all nights with power law curve fitting is seen in the right inset. Values of $h_{\mathrm{V}}$ from 23 March 2015 are marked in red.

face (e.g., Pomeroy and Gray, 1990). This stemmed from the earlier lack of high-resolution measurements of near snow surface processes outdoors, as results were in agreement with later wind tunnel observations (Sugiura et al., 1998; Nishimura and Hunt, 2000) and numerical studies (Nemoto and Nishimura, 2004) of snow flux profiles as well as the recently measured blowing snow density profiles that Gordon and Taylor (2009) and Gordon et al. (2009) found over natural snow covers in Churchill and Franklin Bay, Canada, respectively.

For the time series investigated, mean particle diameters had small temporal variance over any given recording ( $0.01 \mathrm{~mm}$ on 23 March, $0.05 \mathrm{~mm}$ on 3 February, and $0.02 \mathrm{~mm}$ on 3 March). For a given time step, mean particle diameters tended to decrease with height in the field of view, typical of saltating snow studies (e.g., Sugiura et al., 1998; Gromke et al., 2014), with the most extreme variations on the order of
$60 \mu \mathrm{m}$. From this it can be inferred that particle number concentrations were closely related to particle volume fractions through mean diameters, and one can neglect variations in particle size with wind speed changes while admittedly underestimating the relative volume concentration close to the surface.

Particles moving in the densest region of the flow, immediately above the surface, are in a zone where particle tracking by optoelectronic snow particle counters becomes impossible but PTV provides new information. Close to the surface, it is possible to observe the whole spectrum of saltating particle velocities including those considered to be moving via creep.

Similar to the high- and low-energy saltating grain populations theory of Ho et al. (2014), terrain-following height bands were chosen such that two end-case populations could be delimited. Unique descending particles were separated 

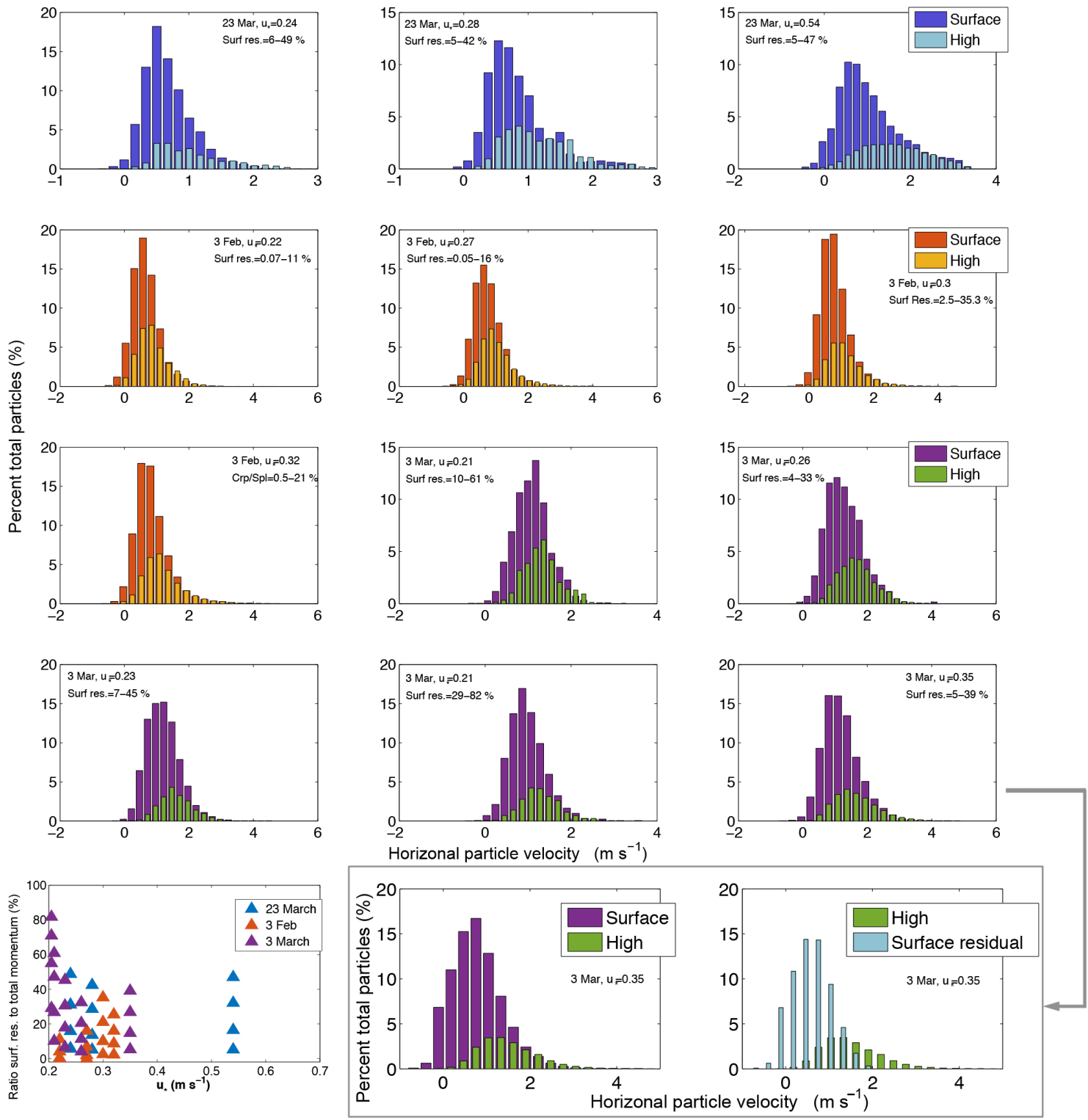

Figure 8. Horizontal particle velocity histograms for near-surface and upper-region descending particles for each recording over the three nights (each colored differently). Near-surface residual highlighted for 3 March no. 5. The two-region delineation was set at $3 \mathrm{~mm}$ for 3 and $23 \mathrm{March}$, and $4 \mathrm{~mm}$ for 3 February. Bottom left: surface residual to total momentum ratios for each recording.

into upper and lower regions according to a variable boundary $(2-5 \mathrm{~mm})$ so that they appear at most once in each region. Then, particles were binned into 20 equivalent size horizontal velocity bins. Figure 8 shows one example of histograms generated by these bins for a given height separation ( $3 \mathrm{~mm}$ for 3 and 23 March, $4 \mathrm{~mm}$ for 3 February). Assuming that most descending particles tracked in the lowest $30 \mathrm{~mm}$ (frame size) will impact the surface, then most descending grains in the upper region will also be present in the lower region. This behavior appears in Fig. 8, where the upper-region population is a subset of the lower-region population, showing that high- and low-energy populations coexist as part of a continuous spectrum of motion at the surface. This is indicative of an inherent coupling of the creep and saltating grain motions. There is sensitivity to the selection of upper and lower regions. With a separation threshold below $2 \mathrm{~mm}$, numbers of high-velocity, low-region particles are underestimated because tracking is increasingly difficult. With the separation threshold above $5 \mathrm{~mm}$, the low density of particles and sensitivity to out of plane wind fluctuations made measurements of representative fluxes inaccurate. Thus, the separation threshold was restricted to the $2-5 \mathrm{~mm}$ range.

For every recording and each separation threshold chosen, there was a denser surface flow whose mean statistics 
are dominated by slow-moving particles. This is to be expected from the particle velocity and number flux profiles in Figs. 6 and 7. The upper-region histograms show saltating particles starting to transition towards higher-energy trajectories, with transport dynamics dominated by larger horizontal velocities. The increasing proportion of high-energy particles with distance from the surface is likely due to the need for a greater velocity to reach greater heights on a ballistic trajectory from the surface and the subjection to higher wind speeds with increasing distance above the surface.

Subtracting the upper-region particle bin numbers from the lower-region bins permits an estimate of the number of particles at given velocities present solely in the lower region, hereon termed the surface residual. The sensitivity analysis showed that for nearly every separation threshold at least as many high velocity particles existed in the upper region as in the lower. This allows conceptualization of the surface residual as the slower-moving surface grains, though not necessarily creep. An example of this is shown in histograms of descending lower-region, upper-region, and surface residual particle horizontal velocities for 3 March recording no. 5 in Fig 8.

Assuming a fixed particle diameter for all particles in each recording as the mean from Fig. 3, spherical snow grains, and a grain density of $917 \mathrm{~kg} \mathrm{~m}^{-3}$, snow transport momentum for each region could be estimated as the sum of momentum of particles in each velocity bin. Varying upper- and lower-region separation thresholds from 2 to $5 \mathrm{~mm}$, the surface residual constituted $2-82,0.07-35$, and $5-49 \%$ of total transport momentum below $30 \mathrm{~mm}$, on 23 March, 3 February, and 3 March respectively. Ranges of momentum contribution for individual recordings are indicated on the respective histograms in Fig. 8 as "Surf Res" and are plotted in the bottom left panel. Surface residual momentum values compliment the profiles of $F_{z}$ (Fig. 7) as near-surface $F_{z}$ values also include high velocity particles that impact the surface.

In the near-surface region, the ability of the snowpack to redistribute impact momentum was estimated from PTV data derived from each recording. Mean snow particle rebound efficiency varied from night to night and was quantified by the restitution coefficient, $\overline{e_{x z}}=\overline{\left\|s_{\mathrm{r}}\right\|} / \overline{\left\|s_{\mathrm{i}}\right\|}$, where $\overline{\left\|s_{\mathrm{r}}\right\|}$ and $\overline{\left\|s_{\mathrm{i}}\right\|}$ are mean ejection and impact speeds of particles, respectively, at $6 \mathrm{~mm} \pm 2 \mathrm{~mm}$, such that the lower bound of the measurement band corresponds with the upper bound of the surface band generating Fig. 8 histograms. Because of the density of the particle flow, and transverse components of travel, a bulk statistical approach must be used to quantify momentum redistribution into the particle bed. Therefore particle ejection speeds of both the rebounding grains and the splashed grains that reach $\sim 20$ particle diameters above the surface were averaged. Over the course of the campaign, $\overline{e_{x z}}$ varied from 0.58 to 0.84 , within the bounds of the previous wind tunnel blowing snow study of Sugiura and Maeno (2000), who used a complimentary particle by particle approach, separating individual rebounding and splashed grains. The mean restitution coefficient was 0.69 for the graupel grains on 23 March, 0.79 for fresh snow on 3 March, and 0.73 for old snow on 3 February. This suggests rebound efficiency was dependent on time-sensitive saltating snow crystal and bed mechanical-material properties, as also noted in a blowing snow wind tunnel study by McElwaine et al. (2004).

\subsection{Turbulent event transport}

The initiation mechanisms observed at the surface during the onset of transport events differ from those proposed in single threshold velocity models (e.g., Schmidt, 1980), suggesting multiple thresholds with the dense surface flow playing a crucial role. All three transport thresholds recognized during video playback were crossed during 23 March recording no. 3 (Fig. 9), when an isolated gust was captured with minimal antecedent transport. Thus, it will be used as an example for further discussion. Concurrent streamwise wind measurements at 200 and $40 \mathrm{~cm}$ are plotted in Fig. 9a, showing penetration of a turbulent sweep to the surface that is responsible for snow transport. In Fig. 9a, filled circles indicate sweep events with RS exceeding 1 standard deviation of total RS (colors corresponding to measurement heights), while triangles indicate similar moments of strong ejections. Figure $9 \mathrm{~b}$ and $\mathrm{c}$ show time series of spatially averaged particle velocities and total particles tracked, respectively, in three height bands: $1<z<4 \mathrm{~mm}$ (near-surface), $4 \leq z<8 \mathrm{~mm}$ (middle), and $8 \leq z<30 \mathrm{~mm}$ (high). These three heights were chosen to demonstrate the subtle differences in particle transport and the continuum of motion as grains began motion and began bouncing to greater heights as wind speeds increased. These are not hard thresholds of "creep" vs. "saltation" regimes. Figure 9d shows the time series of instantaneous blowing snow flux $Q_{\mathrm{s}}$ in $\mathrm{kg} \mathrm{m}^{-2} \mathrm{~s}^{-1}$. These binarization-based flux measurements compliment PTV calculations in intense gusting when enumerating all particles through tracking became difficult.

At the end of a strong ejection event (2.5-4.5 s) at wind speeds near $4 \mathrm{~m} \mathrm{~s}^{-1}$, snow particle motion began with tumbling surface movement where aerodynamic drag was barely able to directly break weak surface crystal bonds and initiate rolling ( $5 \mathrm{~s}$ in Fig. 9b, c, d). Particle-bed collisions were concurrently responsible for breaking surface snowpack matrix structures at these wind speeds, though they were not yet able to initiate a splash regime. The Mar23-15 video in the Supplement for 23 March begins at $5 \mathrm{~s}$ in this time series. The bonds broken by low-energy grains at low wind speeds enabled more grains to be freely available for entrainment. During this time, horizontal particle velocities remained low and in the near-surface region (Fig. 9b), with no particles being tracked above $4 \mathrm{~mm}$ (Fig. 9c) and total mass transport remaining low (Fig. 9d). At this stage, the only particles in motion were those classically termed creep.

As the wind speed increased $(>6 \mathrm{~s})$, another threshold was crossed $\left(\sim 4.5-5 \mathrm{~m} \mathrm{~s}^{-1}\right)$, above which tumbling near- 

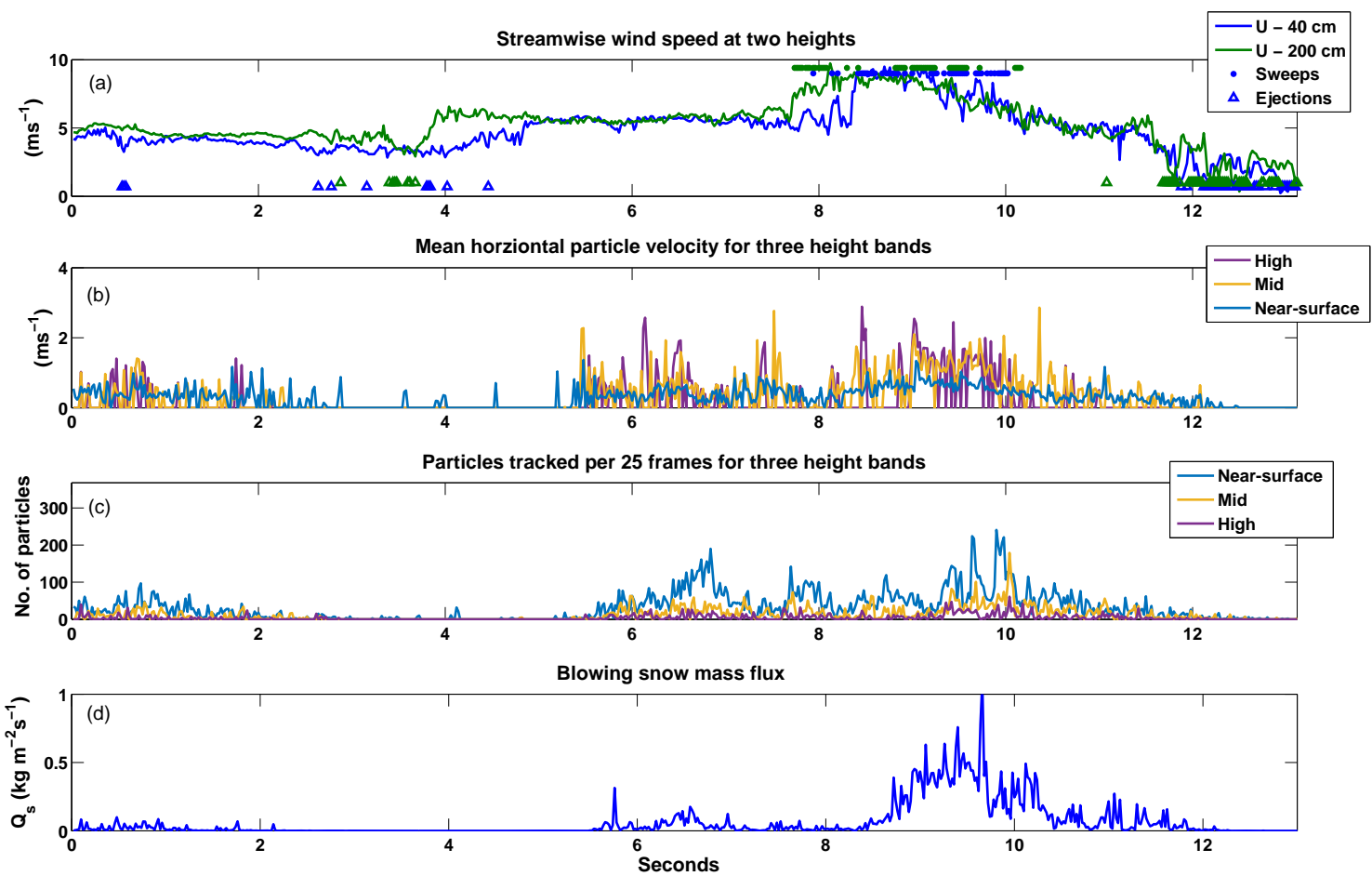

Figure 9. Recording no. 3 time series for $23 \mathrm{March}$ : (a) $50 \mathrm{~Hz}$ streamwise wind speed at 40 and $200 \mathrm{~cm}$ above snow surface; (b) $50 \mathrm{~Hz}$ snow particle velocities obtained by binning particle vectors in three height bands $(1<z<4 \mathrm{~mm}$, near-surface; $4<z<8 \mathrm{~mm}$, middle; $8<z<30 \mathrm{~mm}$, high), then temporally averaged over 25 frames; (c) number of tracked particles in same height bands per 25 frames; (d) instantaneous blowing snow flux rates $Q_{\mathrm{s}}\left(\mathrm{kg} \mathrm{m}^{2} \mathrm{~s}^{-1}\right)(1250 \mathrm{~Hz})$.

surface particles were sufficiently accelerated so that they could regularly bounce off the uneven surface and out of the creep layer. This initiated what is classically described as saltation, evidenced by the increasing presence of particles tracked in the "middle" and "high" regions in Fig. 9c (above $4 \mathrm{~mm}$ ), though snow mass flux remained moderate at this time (Fig. 9d). A continuum of motion is evidenced here as all mean particle velocities increased and velocities steadily increased away from the surface.

At $8 \mathrm{~s}$, a strong sweep is present at $2 \mathrm{~m}$ that penetrates to the surface by $8.5 \mathrm{~s}$ when the last critical wind velocity threshold was crossed $\left(\sim 6 \mathrm{~m} \mathrm{~s}^{-1}\right)$, at which saltating particles were sufficiently accelerated to initiate an active splash regime upon rebounding. At this point snow mass flux increased exponentially (Fig. 9d), abruptly saturating the recording frame with snow particles and limiting illumination for successful PTV (discussed below). Similar exponential increases of sand flux during gust onset and splash commencement have been documented (Willetts et al., 1991). The increased snow mass flux (Fig. 9d) persisted for the duration of the gust, (until $10 \mathrm{~s}$ ) after which both high and low streamwise velocities decreased. From $11 \mathrm{~s}$ onwards, the decreasing wind speed was no longer able to sustain the mass transport and particle counts dropped in the "middle" and "high" regions of flow. A combination of inertia and wind drag prolonged transport in the creep layer, maintaining rolling crystals that continued breaking surface bonds and were available for transport during the next gust.

High region particle velocity spikes occurred with some delay after $8.5 \mathrm{~s}$ due to the intense snow particle density blocked the laser light illumination, making particle tracking difficult. At $9 \mathrm{~s}$, the number of particles tracked in the upper region increased as particles tracked near the surface decreased. This is likely a measurement error due to the dense granular flow attenuating light penetration to the snow surface. As the gust began to subside after $9 \mathrm{~s}$, PTV-observed velocities and particle numbers increased because tracking became more successful. Then, as wind speed decreased further, observed velocities and particle numbers decreased as expected. The Otsu (1979) binarization thresholds were determined over short subperiods $(0.085 \mathrm{~s})$ of recording no. 3 (Fig. 9d), allowing the thresholding technique to adapt to different levels of illumination and overcome these saturation issues.

Particle impact dynamics evolved as snowpack surface conditions varied during the season with multiple meltfreeze cycles, periods of wind hardening and the appearance of mixed grain types. Warm (Air Temp: $+1{ }^{\circ} \mathrm{C}$ ) February 2015 snowstorms precipitated enormous aggregate and rimed crystals that expanded the role of near-surface particle 
dynamics. Large (4 $\mathrm{mm}$ diameter) tumbleweed-like aggregate grains, termed here "tumblons", eroded many smaller crystals from the surface or shattered themselves and immediately became saltating grains, depending on impact velocity. Overlain PTV vectors can be seen in tumblon PTV video in the Supplement, where an impacting tumblon shatters at the surface at $7 \mathrm{~s}$, with an impact velocity of approximately $(u, v)=(2.46,-0.43) \mathrm{m} \mathrm{s}^{-1}$. At $35 \mathrm{~s}$ in the PTV video, a comparably sized tumblon with velocity $(u, v)=$ $(0.6,0.1) \mathrm{m} \mathrm{s}^{-1}$ tumbles across the screen without collapse. This type of particle motion has not been described before and would seem to be a distinctive feature of blowing snow during or shortly after snowfall of large dendritic flakes in relatively warm conditions. Uniquely large grains can also be found in the Mar3-16 video in the Supplement, though shattering dynamics do not appear prevalent on that night as large grains resulted from riming and not wet grain aggregation. Decomposing and aggregate grains of extreme size have not been reported for saltating sand. This may limit the application of sand bed momentum balances and wind tunnel studies where there are no contributions of falling snow to saltation.

\section{Discussion}

Choosing the appropriate timescale to characterize turbulent energy for snow transport is vital. From Table 2 and Figs. 6 and 7, it is clear that recording specific particle velocity gradients $\gamma$ and flux concentration profiles did not scale with $15 \min u_{*}$ or $z_{0}$ values as is assumed on average for many existing snow saltation models (Pomeroy and Gray, 1990). Part of this lack of concurrence was due to intermittent transport and large-scale atmospheric motions generating high shear over short periods (Fig. 4). Also, the limited Reynolds numbers possible in wind tunnel blowing snow experiments cannot replicate the complex eddy structure of the ASL. Thus kinetic energy is contributed to mass transport at much higher frequencies in wind tunnels (Paterna et al., 2016) and the full spectrum of motion can be measured over shorter timescales. Moreover, with the influence of surrounding topography, capturing the relevant range of energy containing eddies to predict snow transport in the alpine is less straightforward. The 15 min mean wind speeds were often below any snow transport thresholds reported in the literature ( $\mathrm{Li}$ and Pomeroy, 1997). The significant errors arising when applying time-averaged values in a $u_{*}$ driven transport model (i.e., Bagnold, 1941) in intermittent winds have been well examined for sand (Sørenson, 1997) and equally apply for snow saltation. Pomeroy and Li (2000) accounted for the inapplicability of steady-state theory in near-threshold conditions by using a probability of occurrence function to reduce transport fluxes at lower mean wind speeds, but it is unclear whether this empirical correction can account for the complex interaction of turbulence and particle flux near the threshold. Disagreements between $u_{*}$ and $z_{0}$ values at the two measurement heights, large $15 \mathrm{~min} z_{0}$ values, and disagreement between log-law-based and covariance-generated $u_{*}$ values reinforces the notion that all required assumptions must be met before log-law profiles should be applied for blowing snow models (George, 2007), especially in complex terrain.

Blowing snow PTV transport profiles were clearly more related to recording-specific $u_{*}$ than $15 \mathrm{~min}$ values because of the non-steady-state nature of the wind. As found in several wind tunnel sand studies (Creyssels et al., 2009; Ho et al., 2011), particle velocity gradients adhered to linear profiles below $\sim 8-12 \mathrm{~mm}$ depending on the night. The low-energy near-surface population of particles was less affected by fluctuations in wind strength (Ho et al., 2014), which resulted in more temporally consistent periods of near-surface low-energy transport and lower NRMSE values. Recent blowing snow wind tunnel experiments found log-linearity present in the horizontal velocity profile (Tominaga et al., 2012), though this was not observed in the present study because of a lack of presence of a log-law for the wind.

For all recordings, the velocity gradients $\gamma$ increased with increasing friction velocity estimates (Fig. 6d, e, f). Thus even in the dense low-energy population of grains, there was noticeable adaptation to changing wind speeds. However, the role of low-energy grains diminished as surface grains became less available with increasing surface hardness. As with the rigid bed experiments from Ho et al., (2011) at similar Shields parameters, there was a much smaller variability in $\gamma$ for the wind-hardened bed on 3 February than for the two nights with lower HHI and lower overall $\gamma$ values. The momentum deficit height $h_{\mathrm{v}}$ was also highest for 3 February (Fig. 7 inset) with relatively low Shields numbers (0.0260.061 ), indicating a muted role of creep and a more uniform saltation layer.

On the same night, a linear increase in particle slip velocity $u_{0}$ was observed for wind-hardened beds, similar to the findings over rigid beds by Ho et al. (2011) for sand. This showed a general acceleration of all grains in saltation when there are fewer new grains to be entrained in the flow. In comparison, there was much less variability for slip velocity for 3 and 23 March over a wider range of Shields parameters and no clear increasing or decreasing trend. A constant slip velocity is characteristic of erodible beds in equilibrium sand transport experiments (Creyssels et al., 2009, Ho et al., 2011). Presumably, as increasing concentration compensates for increasing friction velocity, $u_{0}$ returns to mean values over time. Snow transport observed to be in constant readjustment to changes in wind speed, and equilibrium was never reached in the experiments, though reduced variation in $u_{0}$ may be indicative of early stages of the equilibrium process as theorized by Ungar and Haff (1987).

Particle number flux concentration profiles fit an exponential decrease model with increasing accuracy as height decreased and flow density increased, as predicted in many 
other sand and snow studies (Maeno et al., 1980; Nishimura and Hunt, 2000; Creyssels et al., 2009; Ellis et al., 2009; Ho et al., 2011; Lü et al., 2012). A direct comparison of decay length $\left(l_{\mathrm{V}}\right)$ between recordings and other experiments was impractical because large variations in surface concentration $\left(v_{0}\right)$ skewed the decay length, making it a poor analogue for saltation height. Instead, it was found that the momentum deficit height $h_{\mathrm{v}}$ increased for most recordings with increasing friction velocity. Lower $h_{\mathrm{v}}$ values require more particle transport momentum nearer the surface. The presence of lowenergy near-surface particles at low friction velocities served as a reservoir for the transition to saltation with subsequent increases in wind speed. As the wind speed accelerates, more particles are accelerated and transported to greater heights where they are further accelerated, resulting in a more uniform vertical distribution of mass flux. This occurs gradually with increasing wind speed rather than involving discrete transport threshold velocity values for separate modes of transport.

The notable exception for this trend in $h_{\mathrm{v}}$ were the events of 23 March (Fig. 7, inset - red dots) where $h_{\mathrm{v}}, l_{\mathrm{v}}$, and $v_{0}$ values remained constant as was predicted by Ho et al. (2011) for erodible beds. This difference in behavior can be physically justified as spherical graupel grains over a noncohesive bed are the conditions most closely resembling sand, and so the number flux profiles behaved more similarly to sand than for the other two nights of blowing snow.

Histograms of horizontal velocity further supported the relevant and dynamic role of the low-energy surface population of blowing snow (Fig. 8), and the decreasing importance of near-surface mass flux with increasing surface hardness. The bottom left plot in Fig. 8 shows that for the nights with erodible beds and lower HHI ( 3 and 23 March), the ratio of surface residual to total momentum is largest for low friction velocity. This is not sensitive to the separation threshold height chosen. During low wind speeds, particle transport for the erodible beds was largely confined to the lower region with few high-energy surface impacts. The ratio of surface residual to total momentum, and therefore number flux, was much higher over erodible beds than over the wind-hardened rigid bed recordings on 3 February (Figs. 7, 8). This complimented the fact that the low-energy surface transport on 3 February had the smallest contribution to total number flux. Thus particle type and snow bed properties played a significant role in the surface momentum balance, changing the uniformity of saltation profiles and wind momentum lost to surface transport. Mean particle diameters remained relatively similar over all recordings and thus snow transport models need to account for snow bed hardness or erodibility as there is a connection to a variable near-surface transport momentum sink.

Analyzing the instantaneous wind speeds in Fig. 9a helps to explain the short timescale roles of gusts, high friction velocity, and turbulence intensity for snow transport in recording no. 3. The turbulent sweep event $(u>0, w<0)$ from 8 to $9 \mathrm{~s}$ generated considerable RS; this turbulent structure is widely reported to be involved in initiating aeolian sediment transport (Grass, 1971; Jackson, 1976; Sterk et al., 1998; Chapman et al., 2012). The $1 \mathrm{~s}$ sweep accounted for 29 and $25 \%$ of total absolute RS at 40 and $200 \mathrm{~cm}$, respectively, and contributed $56 \%$ of total snow particle flux below $30 \mathrm{~mm}$, but occupied only $8 \%$ of the time. Turbulent ejections $(u<0$, $w>0$ ) generated $39 \%$ of total absolute shear stress during the recording and contributed the same direction of RS values to friction velocity calculations but only resulted in $3 \%$ of total snow particle flux. Varying the lag time between wind and snow measurements from 0 to $1 \mathrm{~s}$ to determine the resultant snow flux had no significant effect on these calculations.

In this gusty alpine environment, periodic turbulent gusts generated the majority of momentum flux as seen by impact factors greater than unity at the surface for Q2 and Q4 and small contributions from Q1 and Q3 (Fig. 4). More importantly, recording no. 3 showed that the sweep event with strong positive $u$ fluctuation resulted in particle entrainment and transport, whereas the large ejection event was ineffective at generating snow transport. As suggested by Sterk et al. (1998), instantaneous wind speed is a potentially better predictor of snow transport than friction velocity. However, during each night, the mass flux scaled with increasing friction velocity (Table 2). This resiliency may help explain some of the robustness of $u_{*}$-based time-averaged uniform trajectory blowing snow models, but it requires further investigation. The role of sweep events such as this for initiating snow saltation is potentially important for developing models that couple turbulence to snow erosion, entrainment, and mass flux and may help resolve current uncertainty in estimating threshold conditions for transport. The importance of understanding snow response to instantaneous wind speed is further increased in complex terrain where the $300 \mathrm{~m}$ of clear upwind fetch or $60 \mathrm{~s}$ of constant wind suggested by Takeuchi (1980) for saltation to fully develop is not always available. For a more general application, this requires further investigation of turbulent snow transport over longer time series and other snow conditions.

Designating creep as distinct from saltation as originally done by Bagnold (1941) is not only unnecessary but also physically inaccurate as snow transport displays a continuous spectrum of motions, similar to that proposed for sand by Anderson (1987), and individual particles can easily transition from one form of motion to another over their trajectories. However, two populations of motion in this spectrum could be identified in the analysis of Figs. 6-9. While undergoing wind speed fluctuations, the region of near-surface flux has the most temporally consistent transport (Fig. 9). This was also the region of largest velocity variance (Fig. 8), yet the consistent presence of the slow particle flow allowed the best fit of particle number flux and mean particle velocity to profiles suggested in the equilibrium sand transport literature. The worst fit of both gradients always occurred at the upper regions dominated by high-energy particles (Fig. 8). 
These high-energy particles constituted the population of fast-moving grains that was most susceptible to changes in wind speed (Ho et al., 2014) and most temporally intermittent (Fig. 9).

The lower boundary condition for momentum transfer is complex due to creep and dependent on instantaneous wind speed and turbulent motions near the surface. As a result, equilibrium conditions were never found in the field observations reported here. Nonequilibrium saltation-wind interactions cannot be described with simple uniform trajectories. The majority of particle trajectories in saltation consist of short hop lengths and times, resulting in high frequencies of particle collisions that break surface bond structures and create dense quasi-fluidized bed characteristics. The complexity of conservation of mass, momentum, and kinetic energy in blowing snow in natural environments, such as measured here, cannot be understated, especially when the large rimed, aggregate tumblons were present. In the alpine snowpacks investigated, variable particle restitution coefficients contributed to this complexity. While high HHI windhardened surfaces exhibited similar behavior of slip velocity and particle velocity gradients as rigid bed sand studies, complexities over a natural snowpack prevented conclusive bimodal "erodible" vs. "nonerodible" scale relations that appear to be viable for sand (Ho et al., 2011). Blowing snow is a distinctive two-phase flow.

Despite arguments to the contrary for other materials (e.g., Sterk et al., 1998), saltating snow models relate mass flux to surface shear stress estimated from air motions well above the surface. These estimates are often based on a momentum deficit derived from the total number of particles in transport, neglecting the vertical heterogeneity of particle concentration and momentum within the snow saltation layer (Doorschot and Lehning, 2002). As all panels in Figs. 6 and 7 show, uniform descriptions of surface shear stress calculations based on concentration and flux measurements above $10 \mathrm{~mm}$ overlook the substantial wind momentum transferred into the creep layer (i.e., Zhang et al., 2007; Creyssels et al., 2009; Ho et al., 2011, 2012, 2014). Disregarding this flux prevents calculation of the full momentum balance. Accounting for variability in saltation trajectories would also allow for a dense surface flow to be represented that can feed upper regions (e.g., Nemoto and Nishimura, 2004) and create a self-consistent momentum balance. Andreotti (2004) wrote a further discussion of self-consistency errors of wind feedback in single trajectory saltation models.

The wide variety of snow saltation initiation mechanisms observed in this experiment is in contrast to classic initiation models that assume that a temporally constant fraction of saltating grains begin motion through either aerodynamic entrainment or splash (e.g., Pomeroy and Gray, 1990). As seen in Fig. 9 and the video in Supplement, in intermittent conditions this variability is magnified, as splash regimes themselves are intermittent and depend on sufficient wind speed for adequate particle acceleration upon ejection from the snow surface.

\section{Conclusion}

This is the first investigation to measure outdoor snow particle flux and velocity immediately above the snow surface. It provides an opportunity to test certain observations of saltating particle flux trajectories measured in wind tunnels. Though observations were restricted to moderate wind speeds and intermittent transport, they show the importance of creep to the initiation of blowing snow transport and the transition to full saltation. Being able to relate high-frequency turbulent wind speed to snow transport (e.g., Guala et al., 2008) is critical in the alpine environment (Naaim-Bouvet et al., 2011) and this study makes a contribution to understanding these dynamics.

PTV has proven to be a viable avenue for exploring complex wind-snow interactions at millisecond timescales in natural, non-steady-state, high Reynolds number wind conditions. These results support the need for further conceptual advancement of models of snow particle movement, including initiation, rebound, multiple types of motion, and the interaction of turbulent sweeps with particle erosion and entrainment. Over short timescales, snow particle motion is influenced by complex wind-speed-dependent initiation and rebound dynamics, including a dense near-surface flow whose presence and variation cannot be described by scalar aerodynamic entrainment and splash parameterizations. Wind-tosnow and snow-to-snow momentum transfer in the first few $\mathrm{mm}$ above the surface is critical for driving mechanisms of transport initiation and providing lower boundary conditions for two-phase atmospheric flows.

The results show a wide spectrum of particle motions exist with near-surface and upper-level snow particle transport intrinsically linked through momentum and mass balances. The relative contributions of near-surface and upper-level transport depend on wind strength and snowpack properties. Sand saltation velocity distribution models do not comprehensively describe transport of complex snow crystal structures such as the previously undescribed tumblon motions or snow particle shattering and sintering. Low-energy nearsurface particles contributed significantly to snow transport as high near-surface particle concentrations compensated for reduced particle speeds and sustained a layer of peak particle momentum and mass flux. The low-energy grains also contributed considerably to saltation by being a reservoir of particles bouncing into saltation and by breaking snow bed matrix bonds, thus making particles more available by reducing the wind drag required for splash and entrainment.

The ability of the snowpack surface to absorb wind and particle momentum in the dense near-surface region of particle transport appears variable and substantial. The role that low-energy near-surface particles play in the wind-snow 
momentum balance and mass flux appeared dependent on snow surface hardness. Wind-hardened surfaces shared several trends similar to that of rigid sand beds, though not all wind tunnel observations could be replicated. As saltation dynamics are dependent upon creep particle motions, which mediate exchange between the snow surface and blowing snow, creep dynamics changes over varying surface hardness also result in changes in saltation, such as changes in velocity gradients, particle concentration, and rebound dynamics. Therefore the near-surface snow transport has far more intricate dynamics and greater flux relevance than previously described.

In the present study, the near-surface particle velocities reflected instantaneous wind speed fluctuations and never achieved equilibrium. As the snow transport was in constant readjustment to changes in wind velocity, and short timescale turbulence characteristics did not scale with long time averages, further characterizations of the timescale of relevance or relevant turbulence scaling relations in alpine terrain need to be performed before a steady-state equilibrium type saltation model (e.g., Pomeroy and Gray, 1990; Doorschot and Lehning, 2002) can be deemed appropriate for these situations. Furthermore, as contributions of shear stress from different RS quadrants are spatially and temporally variable and the mechanics of transport vary during gusts as seen in Sect. 3.3, the need to account for variable shear stress in high-resolution modeling (Doorschot et al., 2004; Groot Zwaaftink et al., 2014) is reinforced.

It could be very useful to compare modeled entrainment and splash ratios with PTV data sets, but longer recording times over a larger variety of snow types would be necessary to obtain statistically significant comparisons. Specifically, whether longer time-averaged statistics can account for periods of varying initiation during intermittent saltation, or can only apply in more nearly steady-state environments, would be a useful finding for high temporal resolution applications (e.g., Groot Zwaaftink et al., 2014). PTV shows potential to answer many open questions in blowing snow research through quantification of momentum redistribution in very near-surface particle motions. The use of high temporal-resolution outdoor PTV measurements may prove useful in future work for understanding how turbulence influences blowing snow processes in natural settings.

\section{Data availability}

Data are available upon request directly from the authors at john.pomeroy@usask.ca.

\section{The Supplement related to this article is available online at doi:10.5194/tc-10-3043-2016-supplement.}

Acknowledgements. The authors acknowledge funding from the Canadian Foundation for Innovation, the Natural Sciences and Engineering Research Council of Canada, the Changing Cold Regions Network, Canada Research Chairs, the Global Institute for Water Security, and Alberta Agriculture and Forestry. The assistance of the Fortress Mountain Resort in logistics is gratefully noted, as are the suggestions from Nicolas Leroux and Florence Naaim-Bouvet to improve the manuscript.

Edited by: G. Chambon

Reviewed by: F. Naaim and one anonymous referee

\section{References}

Anderson, R. S.: Eolian sediment transport as a stochastic process: The effects of a fluctuating wind on particle trajectories, J. Geol., 95, 497-512, doi:10.1086/629145, 1987.

Anderson, R. S. and Haff, P. K.: Simulation of eolian saltation, Science, 241, 820-3, doi:10.1126/science.241.4867.820, 1988.

Andreotti, B.: A two species model of aeolian sand transport, J. Fluid Mech., 510, 47-70, 2004.

Bagnold, R. A.: The physics of blown sand and desert dunes, 1st Edn., Methuen \& Co. Limited, London, 1941.

Bauer, B., Yi, J., Namikas, S., and Sherman, D.: Event detection and conditional averaging in unsteady aeolian systems, J. Arid Environ., 39, 345-375, 1998.

Bintanja, R.: Snowdrift suspension and atmospheric turbulence. Part I: Theoretical background and model description, Bound.Lay. Meteorol., 95, 343-368, 2000.

Brown, T. and Pomeroy, J.: A blowing snow particle detector, Cold Reg. Sci. Technol., 16, 167-174, 1989.

Budd, W. F.: The drifting of non-uniform snow particles, in: Studies in Antarctic Meteorology, edited by: Rubin, M. J., American Geophysical Union, Washington D.C., Antarctic Research Series 9, 59-70, 1966.

Budd, W. F., Dingle, W. R. J., and Radok, U.: The Byrd snow drift project: Outline and basic results, in: Studies in Antarctic Meteorology, edited by: Rubin, M. J., American Geophysical Union, Washington D.C., Antarctic Research Series 9, 59-70, 1966.

Chapman, C. A., Walker, I. J., Hesp, P. A., Bauer, B. O., and Davidson-Arnott, R. G. D.: Turbulent Reynolds stress and quadrant event activity in wind flow over a coastal foredune, Geomorphology, 151-152, 1-12, doi:10.1016/j.geomorph.2011.11.015, 2012.

Creyssels, M., Dupont, P., El Moctar, A. O., Valance, A., Cantat, I., Jenkins, J. T., Pasini, J. M., and Rasmussen, K. R.: Saltating particles in a turbulent boundary layer: experiment and theory, J. Fluid Mech., 625, 47-74, doi:10.1017/S0022112008005491, 2009.

Dennis, D. J. C. and Nickels, T. B.: On the limitations of Taylor's hypothesis in constructing long structures in a turbulent boundary layer, J. Fluid Mech., 614, 197, doi:10.1017/S0022112008003352, 2008.

Doorschot, J. and Lehning, M.: Equilibrium saltation: mass fluxes, aerodynamic entrainment, and dependence on grain properties, Bound.-Lay. Meteorol., 104, 111-130, 2002. 
Doorschot, J., Lehning, M., and Vrouwe, A.: Field measurements of snow-drift threshold and mass fluxes, and related model simulations, Bound.-Lay. Meteorol., 347-368, 2004.

Dyunin, A. K. and Kotlyakov, V.: Redistribution of snow in the mountains under the effect of heavy snow-storms, Cold Reg. Sci. Technol., 3, 287-294, 1980.

Ellis, J. T., Li, B., Farrell, E. J., and Sherman, D. J.: Protocols for characterizing aeolian mass-flux profiles, Aeolian Research, 1, 19-26, doi:10.1016/j.aeolia.2009.02.001, 2009.

Fierz, C., Armstrong, R., Durand, Y., Etchevers, P., Greene, E., McClung, D. M., Nishimura, K., Satyawali, P. K., and Sokratov, S. A.: The international classification for seasonal snow on the ground, The International Classification for Seasonal Snow on the Ground, IHP-VII Technical Documents in Hydrology No 83, IACS Contribution No 1, UNESCO-IHP, Paris, 2009.

Foken, T. and Wichura, B.: Tools for quality assessment of surfacebased flux measurements, Agr. Forest Meteorol., 78, 83-105, doi:10.1016/0168-1923(95)02248-1, 1996.

George, W. K.: Is there a universal log law for turbulent wall-bounded flows?, Philos. T. R. Soc. A., 365, 789-806, doi:10.1098/rsta.2006.1941, 2007.

Gordon, M. and Taylor, P. A.: Measurements of blowing snow, Part I: Particle shape, size distribution, velocity, and number flux at Churchill, Manitoba, Canada, Cold Reg. Sci. Technol., 55, 6374, doi:10.1016/j.coldregions.2008.05.001, 2009.

Gordon, M., Savelyev, S., and Taylor, P. A.: Measurements of blowing snow, part II: Mass and number density profiles and saltation height at Franklin Bay, NWT, Canada, Cold Reg. Sci. Technol., 55, 75-85, doi:10.1016/j.coldregions.2008.07.001, 2009.

Grass, A. J.: Structural features of turbulent flow over smooth and rough boundaries, J. Fluid Mech., 50, 233-255, doi:10.1017/S0022112071002556, 1971.

Gromke, C., Horender, S., Walter, B., and Lehning, M.: Snow particle characteristics in the saltation layer, J. Glaciol., 60, 431-439, doi:10.3189/2014JoG13J079, 2014.

Groot Zwaaftink, C. D., Diebold, M., Horender, S., Overney, J., Lieberherr, G., Parlange, M. B., and Lehning, M.: Modelling small-scale drifting snow with a lagrangian stochastic model based on large-eddy simulations, Bound.-Lay. Meteorol., 153, 117-139, doi:10.1007/s10546-014-9934-2, 2014.

Guala, M., Manes, C., Clifton, A., and Lehning, M.: On the saltation of fresh snow in a wind tunnel: Profile characterization and single particle statistics, J. Geophys. Res., 113, F03024, doi:10.1029/2007JF000975, 2008.

Helgason, W. and Pomeroy, J.: Uncertainties in estimating turbulent fluxes to melting snow in a mountain clearing, in: Proceedings of the 62nd Annual Eastern Snow Conference, 8-10 June 2005, Waterloo, ON, Canada, 129-142, 2005.

Ho, T. D., Valance, A., Dupont, P., and Ould El Moctar, A.: Scaling laws in aeolian sand transport, Phys. Rev. Lett., 106, 4-7, doi:10.1103/PhysRevLett.106.094501, 2011

Ho, T. D., Dupont, P., Ould El Moctar, A., and Valance, A.: Particle velocity distribution in saltation transport, Phys. Rev. E, 85, 1-5, doi:10.1103/PhysRevE.85.052301, 2012.

Ho, T. D., Valance, A., Dupont, P., and Ould El Moctar, A.: Aeolian sand transport: Length and height distributions of saltation trajectories, Aeolian Research, 12, 65-74, doi:10.1016/j.aeolia.2013.11.004, 2014.
Hutchins, N., Chauhan, K., Marusic, I., Monty, J., and Klewicki, J.: Towards reconciling the large-scale structure of turbulent boundary layers in the atmosphere and laboratory, Bound.-Lay. Meteorol., 145, 273-306, doi:10.1007/s10546-012-9735-4, 2012.

Jackson, R. G.: Sedimentological and fluid-dynamic implications of the turbulent bursting phenomenon in geophysical flows, J. Fluid Mech., 77, 531-560, doi:10.1017/S0022112076002243, 1976.

Kinar, N. J. and Pomeroy, J. W.: Measurement of the physical properties of the snowpack, Rev. Geophys., 53, 481-544, doi:10.1002/2015RG000481, 2015.

Kobayashi, D.: Studies of snow transport in low-level drifting snow, Contributions from the Institute of Low Temperature Science, A24, 1-58, 1972.

Li, L. and Pomeroy, J. W.: Estimates of threshold wind speeds for snow transport using meteorological data, J. Appl. Meteorol., 36, 205-213, 1997.

Lü, X., Huang, N., and Tong, D.: Wind tunnel experiments on natural snow drift, Science China Technological Sciences, 55, 927 938, doi:10.1007/s11431-011-4731-3, 2012.

Maeno, N., Araoka, K., and Nishimura, K.: Physical aspects of the wind-snow interaction in blowing snow, Journal of the Faculty of Science, Hokkaido University, Series 7, Geophysics, 6, 127-141, 1980.

McElwaine, J. N., Maeno, N., and Sugiura, K.: The splash function for snow from wind-tunnel measurements, Ann. Glaciol., 38, 7178, 2004

Morris, S. C., Stolpa, S. R., Slaboch, P. E., and Klewicki, J. C.: Near-surface particle image velocimetry measurements in a transitionally rough-wall atmospheric boundary layer, J. Fluid Mech., 580, 319-338, doi:10.1017/S0022112007005435, 2007.

Naaim-Bouvet, F., Naaim, M., Bellot, H., and Nishimura, K.: Wind and drifting-snow gust factor in an Alpine context, Ann. Glaciol., 52, 223-230, doi:10.3189/172756411797252112, 2011.

Nemoto, M. and Nishimura, K.: Numerical simulation of snow saltation and suspension in a turbulent boundary layer, J. Geophys. Res., 109, D18206, doi:10.1029/2004JD004657, 2004.

Nishimura, K. and Hunt, J. C. R.: Saltation and incipient suspension above a flat particle bed below a turbulent boundary layer, J. Fluid Mech., 417, 77-102, doi:10.1017/S0022112000001014, 2000.

Nishimura, K., Yokoyama, C., Ito, Y., Nemoto, M., Naaim-Bouvet, F., Bellot, H., Fujita, K., Yokoyama, C., Ito, Y., Nemoto, M., Naaim-bouvet, F., Bellot, H., and Fujita, K.: Snow particle speeds in drifting snow, J. Geophys. Res.-Atmos., 119, 9901-9913, doi:10.1002/2014JD021686, 2014.

Otsu, N.: A threshold selection method from gray-level histograms, IEEE T. Syst. Man Cyb., 9, 62-66, 1979.

Owen, P. R.: Saltation of uniform grains in air, J. Fluid Mech., 20, 225-242, doi:10.1017/S0022112064001173, 1964.

Paterna, E., Crivelli, P., and Lehning, M.: Decoupling of mass flux and turbulent wind fluctuations in drifting snow, Geophys. Res. Lett., 43, 4441-4447, doi:10.1002/2016GL068171, 2016.

Pomeroy, J., Fang, X., and Ellis, C.: Sensitivity of snowmelt hydrology in Marmot Creek, Alberta, to forest cover disturbance, Hydrol. Process., 26, 1891-1904, doi:10.1002/hyp.9248, 2012.

Pomeroy, J. W. and Gray, D.: Saltation of snow, Water Resour. Res., 26, 1583-1594, 1990. 
Pomeroy, J. W. and Gray, D. M.: Snowcover Accumulation, Relocation and Management, National Hydrology Research Institute, Saskatoon, SK, NHRI Science Report No. 7, 1995.

Pomeroy, J. W. and Li, L.: Prairie and Arctic areal snow cover mass balance using a blowing snow model, J. Geophys. Res., 105, 26619-26634, 2000.

Pomeroy, J. W. and Male, D. H.: Steady-state suspension of snow, J. Hydrol., 136, 275-301, doi:10.1016/0022-1694(92)90015-N, 1992.

Pruppacher, H. R. and Klett, J. D.: Microphysics of Clouds and Precipitation, 2nd Edn., Kluwer Academic Publishers, Dordrecht, The Netherlnds, 954 pp., 1997.

Rosi, G. A., Sherry, M., Kinzel, M., and Rival, D. E.: Characterizing the lower log region of the atmospheric surface layer via large-scale particle tracking velocimetry, Exp. Fluids, 55, 1736, doi:10.1007/s00348-014-1736-2, 2014.

Schmidt, R. A.: Threshold wind-speeds and elastic impact in snow transport, J. Glaciol., 26, 453-467, 1980.

Schmidt, R. A.: Vertical profiles of wind speed, snow concentration, and humidity in blowing snow, Bound.-Lay. Meteorol., 23, 223246, doi:10.1016/j.soncn.2013.06.001, 1982.

Schmidt, R. A.: Measuring particle size and snowfall intensity in drifting snow, Cold Reg. Sci. Technol., 9, 121-129, 1984.

Schweizer, J., Jamieson, B., and Schneebeli, M.: Snow avalanche formation, Rev. Geophys., 41, 1016, doi:10.1029/2002RG000123, 2003.

Sørensen, M.: On the effect of time variability of the wind on rates of aeolian sand transport, Aarhus Geoscience, 7, 73-77, 1997.

Sterk, G., Jacobs, A. F. G., and Van Boxel, J. H.: The effect of turbulent flow structures on saltation sand transport in the atmospheric boundary layer, Earth Surf. Proc. Land., 23, 877887, doi:10.1002/(SICI)1096-9837(199810)23:10<877::AIDESP905>3.0.CO;2-R, 1998.

Stull, R.: An introduction to boundary layer meteorology, Kluwer Academic Publisher, Dordrecht, The Netherlands, 1988.

Sugiura, K. and Maeno, N.: Wind-tunnel measurements of restitution coefficients and ejection number of snow particles in drifting snow: determination of splash functions, Bound.-Lay. Meteorol., 95, 123-143, 2000.

Sugiura, K., Nishimura, K., Maeno, N., and Kimura, T.: Measurements of snow mass flux and transport rate at different particle diameters in drifting snow, Cold Reg. Sci. Technol., 27, 83-89, doi:10.1016/S0165-232X(98)00002-0, 1998.
Tabler, R. D.: Snow transport as a function of wind speed and height, in: Cold Regions Engineering. Proceedings, Cold Regions Sixth International Specialty Conference TCCP/ASCE Cold Regions Engineering, 26-28 February 1991, West Lebanon, NH, 729-738, 1991.

Takeuchi, M.: Vertical profile and horizontal increase of drift-snow transport, J. Glaciol., 26, 481-492, 1980.

Toloui, M., Riley, S., Hong, J., Howard, K., Chamorro, L. P., Guala, M., and Tucker, J.: Measurement of atmospheric boundary layer based on super-large-scale particle image velocimetry using natural snowfall, Exp. Fluids, 55, 1737, doi:10.1007/s00348-0141737-1, 2014.

Tominaga, Y., Okaze, T., Mochida, A., Sasaki, Y., Nemoto, M., and Sato, T.: PIV measurements of saltating snow particle velocity in a boundary layer developed in a wind tunnel, J. Visual.-Japan, 16, 95-98, doi:10.1007/s12650-012-0156-8, 2012.

Ungar, J. E. and Haff, P. K.: Steady state saltation in air, Sedimentology, 34, 289-299, doi:10.1111/j.1365-3091.1987.tb00778.x, 1987.

van Boxel, J., Sterk, G., and Arens, S.: Sonic anemometers in aeolian sediment transport research, Geomorphology, 59, 131-147, doi:10.1016/j.geomorph.2003.09.011, 2004.

Vickers, D. and Mahrt, L.: Quality control and flux sampling problems for tower and aircraft data, J. Atmos. Ocean. Tech., 14, 512-526, doi:10.1175/1520 0426(1997)014<0512:QCAFSP>2.0.CO;2, 1997.

Willetts, B. B., McEwan, J., and Rice, M. A.: Initiation of motion of quartz sand grains, Acta Mech., 1, 123-134, 1991.

Willmarth, W. W. and Lu, S. S.: Structure of the Reynolds stress near the wall, J. Fluid Mech., 55, 65-92, doi:10.1017/S002211207200165X, 1972.

Winstral, A., Marks, D., and Gurney, R.: Simulating wind-affected snow accumulations at catchment to basin scales, Adv. Water Resour., 55, 64-79, doi:10.1016/j.advwatres.2012.08.011, 2013.

Zhang, W., Wang, Y., and Lee, S. J.: Two-phase measurements of wind and saltating sand in an atmospheric boundary layer, Geomorphology, 88, 109-119, doi:10.1016/j.geomorph.2006.10.017, 2007.

Zhu, W., van Hout, R., and Katz, J.: PIV measurements in the atmospheric boundary layer within and above a mature corn canopy Part II: Quadrant-hole analysis, J. Atmos. Sci., 64, 2825-2838, doi:10.1175/JAS3990.1, 2007. 